\title{
Malva parviflora extract ameliorates the deleterious effects of a high fat diet on the cognitive deficit in a mouse model of Alzheimer's disease by restoring microglial function via a PPAR- $\gamma$-dependent mechanism
}

Elisa Medrano-Jiménez ${ }^{1 \dagger}$, Itzia Jiménez-Ferrer Carrillo ${ }^{1 \dagger}$, Martha Pedraza-Escalona ${ }^{1 \dagger}$, Cristina E. Ramírez-Serrano ${ }^{1}$, Lourdes Álvarez-Arellano 1,3, Javier Cortés-Mendoza', Maribel Herrera-Ruiz², Enrique Jiménez-Ferrer², Alejandro Zamilpa², Jaime Tortoriello², Gustavo Pedraza-Alva ${ }^{1}$ and Leonor Pérez-Martínez ${ }^{1 *}$ (i)

\begin{abstract}
Background: Alzheimer's disease (AD) is a neuropathology strongly associated with the activation of inflammatory pathways. Accordingly, inflammation resulting from obesity exacerbates learning and memory deficits in humans and in animal models of AD. Consequently, the long-term use of non-steroidal anti-inflammatory agents diminishes the risk for developing AD, but the side effects produced by these drugs limit their prophylactic use. Thus, plants natural products have become an excellent option for modern therapeutics. Malva parviflora is a plant well known for its anti-inflammatory properties.

Methods: The present study was aimed to determine the anti-inflammatory potential of M. parviflora leaf hydroalcoholic extract (MpHE) on AD pathology in lean and obese transgenic 5XFAD mice, a model of familial AD. The inflammatory response and Amyloid $\beta(A \beta)$ plaque load in lean and obese 5XFAD mice untreated or treated with MpHE was evaluated by immunolocalization (Iba-1 and GFAP) and RT-qPCR (TNF) assays and thioflavin-S staining, respectively. Spatial learning memory was assessed by the Morris Water Maze behavioral test. Microglia phagocytosis capacity was analyzed in vivo and by ex vivo and in vitro assays, and its activation by morphological changes (phalloidin staining) and expression of CD86, Mgl1, and TREM-2 by RT-qPCR. The mechanism triggered by the MpHE was characterized in microglia primary cultures and ex vivo assays by immunoblot (PPAR-y) and RT-qPCR (CD36) and in vivo by flow cytometry, using GW9662 (PPAR- $\gamma$ inhibitor) and pioglitazone (PPAR-y agonist). The presence of bioactive compounds in the MpHE was determined by HPLC. (Continued on next page)
\end{abstract}

\footnotetext{
* Correspondence: leonor@ibt.unam.mx

†Elisa Medrano-Jiménez, Itzia Jiménez-Ferrer Carrillo and Martha PedrazaEscalona contributed equally to this work.

${ }^{1}$ Laboratorio de Neuroinmunobiología, Departamento de Medicina Molecular y Bioprocesos, Instituto de Biotecnología, Universidad Nacional Autónoma de México (UNAM), A.P. 510-3, CP, 62210 Cuernavaca, Morelos, México

Full list of author information is available at the end of the article
}

(c) The Author(s). 2019 Open Access This article is distributed under the terms of the Creative Commons Attribution 4.0 International License (http://creativecommons.org/licenses/by/4.0/), which permits unrestricted use, distribution, and reproduction in any medium, provided you give appropriate credit to the original author(s) and the source, provide a link to the Creative Commons license, and indicate if changes were made. The Creative Commons Public Domain Dedication waiver (http://creativecommons.org/publicdomain/zero/1.0/) applies to the data made available in this article, unless otherwise stated. 


\begin{abstract}
(Continued from previous page)
Results: MpHE efficiently reduced astrogliosis, the presence of insoluble A $\beta$ peptides in the hippocampus and spatial learning impairments, of both, lean, and obese 5XFAD mice. This was accompanied by microglial cells accumulation around $A \beta$ plaques in the cortex and the hippocampus and decreased expression of M1 inflammatory markers. Consistent with the fact that the MpHE rescued microglia phagocytic capacity via a PPAR- $\gamma / C D 36$-dependent mechanism, the MpHE possess oleanolic acid and scopoletin as active phytochemicals.

Conclusions: M. parviflora suppresses neuroinflammation by inhibiting microglia pro-inflammatory M1 phenotype and promoting microglia phagocytosis. Therefore, M. parviflora phytochemicals represent an alternative to prevent cognitive impairment associated with a metabolic disorder as well as an effective prophylactic candidate for AD progression.
\end{abstract}

Keywords: Alzheimer's Disease, obesity, inflammation, Malva parviflora, microglia, PPAR-y/CD36

\section{Background}

Alzheimer's Disease International Organization has predicted that 81.1 million people aged 60 years or more will be declared with dementias worldwide by the year 2040 [1]. Alzheimer disease $(\mathrm{AD})$ is the main cause of dementia characterized by a progressive impairment in cognitive function (i.e., memory) and premature death [2]. Dystrophic neurites, synapses, and neuron loss result from the twisted strands of the protein tau (tangles) inside neurons and the progressive accumulation of $A \beta$ peptides, which are produced by the consecutive proteolytic cleavage of the amyloid precursor protein (APP) by the $\beta$ - and $\gamma$-secretases [3-5]. Adjacent to the amyloid core, microglial cells are frequently found, whereas astrocytes usually surround the plaques. Both cells types produce pro-inflammatory molecules like cytokines and oxygen-free radicals, among others [6]. The presence of elevated pro-inflammatory cytokine concentrations (interleukin (IL) 1 beta (IL-1ß), interleukin 6 (IL-6), tumor necrosis factor (TNF)) in the AD brain has been associated with neuronal toxicity and cell death [7]. IL- $1 \beta$ is produced as a biologically inactive pro-form and requires to be processed by caspase- 1 for its activation. Caspase- 1 activity is controlled by inflammasomes, which are sensors of danger signals. The relevance of the inflammatory process in memory loss and neurodegeneration resulting from $A \beta$ accumulation was recently shown in $A D$ animal models lacking caspase- 1 or other inflammasome components $[8,9]$. Accordingly, distinct factors that play a role in the onset and progression of $\mathrm{AD}$, including type II diabetes mellitus, hypertension, obesity, and dyslipidemia, have been associated to chronic inflammation [10-12]. In fact, type II diabetes is a major risk factor for dementia and has been directly associated with the $A \beta$ accumulation in the brain, due to deficient brain $A \beta$ clearance resulting from the competition between insulin and the $A \beta$ for binding to the insulin-degrading enzyme [13]. Therefore, obesity and high-fat diet are apparent risk factors for dementia associated with brain insulin resistance. The excess of adipose tissue in obesity regulates adipokines (e.g., adiponectin, omentin, leptin, resistin) critical to metabolism as well as inflammatory cytokines (e.g., IL-1 $\beta$, TNF, and IL-6) that correlate with insulin resistance and hyperinsulinemia [14, 15]. Thus, chronic inflammatory process in the periphery might result in dementia.

Consequently, the long-term use of non-steroidal antiinflammatory agents in humans, such as indomethacin, sulindac, and PPAR- $\gamma$ agonist, such as ibuprofen, rosiglitazone, and pioglitazone, has been directly linked with a low risk for developing $A D$ and decreased $A \beta$ deposition in vitro and in vivo $[16,17]$. Unfortunately, the side effects produced by these drugs limit their prophylactic use. Nevertheless, there are natural products that have been widely used for a long time as a remedy for treating diseases with an inflammatory pathophysiological origin [18]. Experimental evidence indicates that polyphenolic compounds, like flavonoids, phenylpropanoids, and terpenes, among others, counteract inflammation (reviewed in [19]). Recent studies have shown that Malva parviflora (M. parviflora), a plant widely used in traditional medicine in America and Africa, has hypoglycemic, anti-inflammatory, and anti-oxidant effects $[20,21]$. Here we evaluated the long-term effects of a $M$. parviflora hydroalcoholic extract (MpHE) on the development of $\mathrm{AD}$ pathology in obese 5XFAD mice. We show that obesity further promoted $A \beta$ plaques formation in the 5XFAD mice. However, administration of the MpHE reversed obesity-mediated deleterious effects of $A \beta$ deposition on memory and learning. Interestingly, this correlated with microglia-enhanced phagocytic capacity and reduced microglia M1 phenotype activation. Importantly, we demonstrated that $\mathrm{MpHE}$ increases microglia phagocytic activity via a PPAR- $\gamma / \mathrm{CD} 36$-dependent mechanism. The phytochemical analysis of the MpHE showed the presence of two active compounds with antiinflammatory activity, scopoletin and oleanolic acid. Together, our results indicate that the MpHE is a promising candidate as an effective prophylactic for AD development.

\section{Methods}

Preparation of the M. parviflora hydroalcoholic extract

The leaves of $M$. parviflora were collected in Ozumba, state of Mexico. One specimen was deposited in the herbarium of Ethnobotanical Garden of Museum of 
Traditional Medicine and Herbal medicine of INAH Morelos. The species was identified by Margarita Aviles and Macrina Fuentes with the registration number 2048. Plant material was dried in dark conditions at room temperature (RT). Once dried, the plant was milled, by means of a $5 \mathrm{HP}$ equipment, until obtaining $<5-\mathrm{mm}$ particles. Plant material (3 kg) was extracted by infusion process at $60^{\circ} \mathrm{C}$ with an ethanolic solution (60\%). The extraction volume used was $2 \mathrm{~L}$ of solvent per kilogram of plant material. Liquid extract was filtered and concentrated by low-pressure distillation. Semisolid extract was finally dried by lyophilization process, obtaining $11.11 \%$ yield. This hydroalcoholic extract (HE) was submitted to liquid-liquid separation. Water and ethyl acetate phases were obtained with $100 \mathrm{~mL}$ of these solvents for each $5 \mathrm{~g}$ of the crude extract. Samples of $3 \mathrm{mg} / \mathrm{mL}$ of these fractions were used for HPLC analysis. When used for intragastric administration, aqueous suspension of the MpHE (5 mg/mL sterile water) was prepared, stored at $4^{\circ} \mathrm{C}$ and protected from light.

\section{Analysis of compounds in the hydroalcoholic extract of M. parviflora}

Chromatographic analysis was developed by means of Waters equipment constituted by a 2695 separations module and a 2996 photodiode array detector. Separation was carried out by using an RP-18 Supersphere (Merck) column $(125 \times 4 \mathrm{~mm}, 5 \mu \mathrm{m})$. The mobile phase consisted of a gradient system with water (solvent A) and acetonitrile (solvent B). Initial conditions started with $100 \%$ of solvent A (0-1 min), followed by different proportions of solvent A:solvent $B=90: 100$ (2-4 min), 80:20 (5-7 min), 70:30 (8-14 min), 60:40 (15-18 min), 20:80 (19-22 min), 0:100 (23-26 min), and 100:0 (27-28 min). The sample injection volume was $10 \mu \mathrm{L}$ with a $1 \mathrm{~mL} / \mathrm{min}$ flow rate. The detection wavelength was scanned at 190-600 nm. Scopoletin quantification was achieved using a calibration curve, which was constructed by three injections of a solution prepared with a commercial reference of the coumarin standard $(7.812,15.625,31.25,62.5$, and $125 \mu \mathrm{g} / \mathrm{mL})$ (Sigma Aldrich, St Louis, MO, USA). Values of the area under the peak of chromatograms recorded at $345 \mathrm{~nm}$ were used to obtain the equation: $Y=84,221 X-188,219$ $R^{2}=0.9995$. The presence of oleanolic acid in the MpHE was established by comparison of the peak at $25.85 \mathrm{~min}$ with a commercial reference of this triterpene (Sigma Aldrich, St Louis, MO, USA).

\section{Macrophage reporter cells and NF-KB/AP-1 activation}

We used a commercially available reporter macrophage cell line (RAW-Blue cells, InvivoGen, San Diego, CA, USA), which expresses the secreted embryonic alkaline phosphatase (SEAP) gene under the control of a promoter inducible by the transcription factors NF- $\mathrm{KB}$ and AP-1. Briefly, cells were seeded in 24-well plates in Dulbecco's
Modified Eagle Medium (DMEM), $4.5 \mathrm{~g} / \mathrm{l}$ glucose, 10\% heat-inactivated FBS $\left(30 \mathrm{~min}\right.$ at $\left.56^{\circ} \mathrm{C}\right), 2 \mathrm{mM}$ L-glutamine, $100 \mathrm{mg} / \mathrm{mL}$ Normocin, and $200 \mathrm{mg} / \mathrm{mL}$ Zeocin. Then, cells were treated with lipopolysaccharide (LPS; $100 \mathrm{ng} / \mathrm{mL}$ ) alone or together with three different concentrations of $\operatorname{MpHE}(0.1,0.5$, and $1.0 \mathrm{mg} / \mathrm{mL})$, oleanolic acid $(15,26$, $40 \mu \mathrm{g} / \mathrm{mL})$ or scopoletin $(3,8,24 \mu \mathrm{g} / \mathrm{mL})$ for $12 \mathrm{~h}$. In addition, cells were pre-treated with LPS or MpHE for 30 min, and then MpHE or LPS was added for $12 \mathrm{~h}$. NF- $\mathrm{kB}$ and AP-1 activity was evaluated indirectly by quantifying the SEAP activity in the culture supernatants. Briefly, 50 $\mu \mathrm{L}$ from each sample were added to $150 \mu \mathrm{L}$ of the QUANTI-Blue assay buffer (InvivoGen, San Diego, CA, USA) and incubated at $37^{\circ} \mathrm{C}$ for $30 \mathrm{~min}$. PBS or the used vehicle to dissolve oleanolic acid or scopoletin were used as negative control. Absorbance at $650-\mathrm{nm}$ wavelength was measured and the SEAP activity was calculated as fold change for each sample (SEAP activity in medium from treated cells minus background (medium without cells) over SEAP activity in medium from untreated cells minus background). In parallel, trypan blue staining was used to determine the cell viability after MpHE treatment.

\section{Animals}

The 5XFAD transgenic mice, expressing the human APP gene with three familial AD mutations (Swedish (K670N, M671L), Florida (I716V), and London (V717I)) and the human presenilin 1 carrying two mutations (M146L and L286V) were obtained from The Jackson Laboratory (Bar Harbor, ME, USA). Mice were housed in groups of five per cage, in a temperature- $\left(22 \pm 1^{\circ} \mathrm{C}\right)$ and humidity-controlled room, with a 12-h light/dark cycle. Food and water were available ad libitum. All tests were performed during the light cycle. Male 5XFAD mice and male wild type (Wt) littermates were used (C57BL/SJL genetic background). Transgenic and Wt mice (6 weeks old) were fed with normal diet (ND) (caloric percentage, 18\%, $3.1 \mathrm{kcal} / \mathrm{g}$; Teklad, Harlan Laboratories), or with a high-fat diet (HFD) (caloric percentage, $60 \%, 5.24 \mathrm{kcal} / \mathrm{g}$; Research diets. Inc, USA). These groups of mice received $50 \mathrm{mg} / \mathrm{kg} /$ day of the $\mathrm{MpHE}$ or water (vehicle) intragastrically during 8 months. Two additional groups from Wt ND and Wt ND treated with $\mathrm{MpHE}$ (C57BL genetic background) were included to determine spatial learning.

For the dose-response experiments, a LPS-mediated neuroinflammation model was used. CD1 male mice were intraperitoneally injected with $125 \mu \mathrm{g} / \mathrm{kg}$ of LPS or vehicle as control for 7 consecutive days. LPS injected mice then received 25,50 , or $100 \mathrm{mg} / \mathrm{kg} /$ day of the $\mathrm{MpHE}$ or water (vehicle) intragastrically during 7 days. Spatial learning and memory were determined. The Institutional Bioethical Committee approved all animal experiments described in this study. 


\section{Metabolic analysis}

Food intake and body weight were measured weekly. After 7 months of treatment, glucose tolerance test (GTT) was performed after $6 \mathrm{~h}$ food deprivation by intraperitoneal (i.p.) glucose administration ( $1.8 \mathrm{~g} / \mathrm{kg}$ body weight). Blood glucose concentrations were measured before glucose administration $(t=0)$ and $15,30,60$, and $120 \mathrm{~min}$ after injection. One month after, insulin resistance test (IRT) was performed after $6 \mathrm{~h}$ food deprivation by i.p. injection of insulin (Humulin ${ }^{\circ} \mathrm{R} 1 \mathrm{mU} / \mathrm{gram}$ of body mass). Blood glucose concentrations were measured before insulin administration $(t=0)$ and $15,30,60$, and $120 \mathrm{~min}$ after insulin administration using a Glucometer (Accucheck; Roche) and the data were reported as milligrams per deciliter. Area under the curve (AUC) for glucose concentration in both cases was calculated as reported previously [22].

\section{Immunofluorescence}

Mice were anesthetized with ketamine/xylazine $(90 \mathrm{mg} /$ $\mathrm{kg} / 9 \mathrm{mg} / \mathrm{kg}$, i.p.) and perfused transcardially with isotonic saline followed by $4 \%$ paraformaldehyde (PFA) in phosphate buffer saline (PBS; pH 7.4). Brains were post-fixed in $4 \%$ PFA overnight, followed by $30 \%(w / v)$ sucrose solution at $4{ }^{\circ} \mathrm{C}$. Immunofluorescence was performed by the freefloating antibody staining method, using $30-\mu \mathrm{m}$-thick sagittal cryostat slices. The slices were washed three times with PBS-T (0.25\% Triton X-100 in PBS) for 5 min each and incubated in blocking buffer (PBS-T $0.1 \%$ bovine serum albumin) for $1 \mathrm{~h}$ at RT. Then, the slices were incubated with mouse monoclonal antibody against Glial fibrillary acidic protein (GFAP) (AB_561049; 1:250) overnight at $4{ }^{\circ} \mathrm{C}$, washed with PBS-T two times for $5 \mathrm{~min}$ each and incubated with secondary antibody goat antimouse Alexa Flour 488 (AB_2534069; 1:400) in blocking buffer for $2 \mathrm{~h}$ at RT. After 2 washes with PBS-T, freefloating brain slices were then mounted with Fluoroshield (Sigma Aldrich Inc) and sealed with a coverslip. Additionally, goat antibody anti-Iba1 (AB_2224402; 1:200) and the secondary antibody donkey anti-goat Alexa Fluor 568 (AB_175704; 1:200, Abcam Inc) were used to identify microglial cells in the brain sections. Images were captured using the Zeiss Axioskop Observer Z1 inverted fluorescence microscope.

\section{Thioflavin-S staining}

PFA-fixed brain tissues of each group were stained in $1 \%$ aqueous Thioflavin-S for $5 \mathrm{~min}$. After this, slices were washed sequentially in $80 \%$ ethanol, $70 \%$ ethanol, and distilled water, then dried and mounted as above described. The brain slices stained with Thioflavin-S were analyzed in a Zeiss Axioskop microscope using an emission spectrum of $550 \mathrm{~nm}$. Images were captured using the Zeiss Axioskop fluorescence microscope. Two or three slices were analyzed in four animals/group. Analyses were performed across the dentate gyrus using a $\times 5$ objective and the automated target detection mode from Image J software (National Institutes of Health, Bethesda, MD, USA). Image size was $1800 \times 1800 \mu \mathrm{m}$ and the percentage of load area was calculated (load area/total area). Additionally, to determine the fraction of amyloid plaques overlapping with microglia in the hippocampus and cortex from 5XFAD mice administered with vehicle or MpHE, the Manders's coefficient was determined using the plugin JacoP [23] in Image J software (National Institutes of Health, Bethesda, MD, USA).

\section{Behavioral assessment of cognitive functions by Morris water maze test}

Spatial learning memory was assessed by the Morris Water Maze behavioral test. Mice were tested in a 1.83 $\mathrm{m}$ circular pool filled with water mixed with nontoxic white paint (titanium oxide). The tank was divided into four quadrants (NW, SW, SE, and NE) of equal size. Mice were trained to mount a hidden/submerged (1.0 $\mathrm{cm}$ below water surface) escape platform (15- $\mathrm{cm}$ diameter) in a restricted region of the pool (NW). Mice were trained for 5 consecutive days from the four quadrants of the tank; they were placed into the water facing the wall and were allowed to swim for a maximum of $90 \mathrm{~s}$. The trial ended when a mouse climbed onto the platform or after the 90-s interval had elapsed. If a mouse did not locate the platform during a trial, it was placed on the platform by the experimenter during $20 \mathrm{~s}$, and then moved to a holding cage. Escape latencies to the hide platform during the learning phase were analyzed using the integrated time traveled and time needed to reach the platform (AUC) for each group. After two days, a memory test was performed in absence of the platform. Mice were released from the four start points to the platform location and allowed to swim freely in the pool for $90 \mathrm{~s}$. Escape latency and swimming paths were recorded.

\section{Microglial cell culture}

Primary cultures of microglial cells were prepared from neonatal (postnatal days 1-3) CD1 mice or from 8- and 10-months-old Wt and 5XFAD mice. Briefly, neonatal brain tissues were mechanically dissociated, treated with Trypsin $(0.25 \mathrm{mg} / \mathrm{mL}$, Sigma Aldrich Inc) and DNase I $(0.28 \mathrm{mg} / \mathrm{mL})$ at $37^{\circ} \mathrm{C}$ for $30 \mathrm{~min}$. After extensive washing, dispersed brain cells were plated as mixed glia cultures (enriched with microglial and astroglia cells) at the density of two brains per dish in DMEM/F12 medium supplemented with $10 \% \mathrm{FBS}, 2 \mathrm{mM}$ glutamine, and antibiotics onto $100-\mathrm{mm}$ Petri dishes at $37^{\circ} \mathrm{C}$ and $5 \% \mathrm{CO}_{2}$. Eight days after plating, the microglia cells were separated from astrocytes by shaking for $5 \mathrm{~h}$ at $250 \mathrm{rpm}$ at $\mathrm{RT}$. The neonatal microglial cultures purity was analyzed 
by flow cytometry, RT-PCR, and immunofluorescence assays using specific markers for microglia (F4/80), $\mathrm{CD} 11 \mathrm{~b}$, astrocytes (GFAP), and neurons (neurofilament $\mathrm{M})$. The antibody anti-F4/80 (AB_1140040; 1.200), antiCD11b (AB_389305; 1:2000), and anti-GFAP (AB_ $561049 ; 1: 200)$ were used for this purpose.

Alternatively, adult brain tissue from wild type and 5XFAD mice was mechanically dissociated and the Neural Tissue Dissociation Kit (Miltenyi Biotec, USA) was used to obtain single-cell suspension. The myelin debris was removed with the Myelin Removal Beads II (Miltenyi Biotec, USA), and the microglia were isolated by positive selection using the CD11b (microglia) microbeads (Miltenyi Biotec, USA), according to the manufacturer's instructions. The adult microglial cultures purity was analyzed by flow cytometry assays using anti-CD11b antibody ( $\mathrm{AB}_{-}$ $389305 ; 1: 2000)$.

\section{Microglia classical activation}

Neonatal primary microglial cultures $\left(1 \times 10^{5}\right.$ cells per well) were plated onto Lab-Tek coverglass chamber wells (Nalge Nunc International, Rochester, NY, USA). After 1 day, the cells were stimulated with $100 \mathrm{ng} / \mathrm{mL}$ LPS in the presence or absence of $\mathrm{MpHE}(1 \mathrm{mg} / \mathrm{mL})$ for $24 \mathrm{~h}$. Control cells were treated with PBS or MpHE alone. Subsequently, the cells were fixed in 4\% PFA for $30 \mathrm{~min}$ at RT and permeabilized with PBS containing 0.1\% Triton TX-100 for $30 \mathrm{~min}$ at RT. F-actin was visualized by incubating cells for $1 \mathrm{~h}$ in the dark with Alexa Fluor 488-conjugated phalloidin (AB_2315147; 1:500). Cell nuclei were labeled with $4{ }^{\prime}$, 6-diamidino-2-phenylindole (DAPI, 1:5000, Molecular probes) for $15 \mathrm{~min}$. Microglial cells were imaged using the Olympus FluoView 1000 confocal multiphoton microscope. The different microglial cell morphologies (amoeboid, ramified, and intermediate shapes) were quantified in each treatment from seven random fields per group. The length of the protrusions of the microglial cells was determined using Neurite Tracer plugin from ImageJ software (National Institutes of Health, Bethesda, MD).

\section{In vitro phagocytosis assay}

Eight days after separating astroglial cells, microglia from eight and 10-months-old Wt and 5XFAD mice were plated onto Lab-Tek coverglass chamber wells $\left(1 \times 10^{5}\right.$ cells per well) (Nalgene Nunc International, Rochester, NY, USA) and treated with MpHE $(1 \mathrm{mg} / \mathrm{mL})$ for $24 \mathrm{~h}$. The medium was then replaced with fresh medium containing $1 \times 10^{6}$ fluorescent E. coli bacteria [24] or unlabeled latex beads $(0.8 \mu \mathrm{m}$ diameter) (Calibrite, Becton Dickinson), and incubated for 1 or $4 \mathrm{~h}$, respectively. The medium was removed, the microglial cells were washed extensively with PBS, treated with Geneticin $(20 \mu \mathrm{g} / \mathrm{mL})$ for $30 \mathrm{~min}$, and fixed in 4\% PFA (Sigma Aldrich Inc) for
$30 \mathrm{~min}$ at RT. Then, cells were permeabilized with PBS containing $0.1 \%$ Triton TX-100 for $30 \mathrm{~min}$ at RT. Actin and the nucleus were visualized as described above. The percentage of cells capable of internalizing $E$. coli bacteria and the average of $E$. coli ingested by cells were determined. The phagocytosis index was determined by multiplying the percentage of microglial cells with internalized bacteria by the average number of internalized $E$. coli bacteria [25] or unlabeled latex beads for each sample. Data were collected from seven random fields per group. Microglial cells were imaged using the Olympus FluoView 1000 confocal multiphoton microscope.

\section{PPAR- $\gamma$ protein levels and ex vivo phagocytosis assay}

Neonatal primary microglial cultures $\left(2.5 \times 10^{5}\right.$ cells $)$ were left untreated or pre-treated with $100 \mu \mathrm{M}$ GW9662, a specific PPAR- $\gamma$ inhibitor. After $1 \mathrm{~h}$, cultures were treated with MpHE $(0.1$ and $1 \mathrm{mg} / \mathrm{mL})$ or with pioglitazone $(10 \mu \mathrm{M}$; a PPAR- $\gamma$ agonist $)$ or with oleanolic acid $(4.5 \mu \mathrm{g} / \mathrm{mL}$ and $45 \mu \mathrm{g} / \mathrm{mL})$ for $24 \mathrm{~h}$. The PPAR- $\gamma$ levels from the cell extracts were determined by immunoblot. Additionally, PPAR- $\gamma$ levels were also determined in the frontal cortex cell extracts of 5XFAD and $\mathrm{Wt}$ mice fed with either ND or HFD non-treated (vehicle) or treated with MpHE.

Ex vivo $A \beta$ phagocytosis assays were performed as previously described [26]. Briefly, adult 5XFAD transgenic mice were perfused with saline solution. Brains were removed and snap frozen in dry ice. After, $10-\mu \mathrm{m}$-thick sagittal cryostat slices were obtained and mounted onto poly-D-lysine-coated glass coverslips. Brain slices were dried for at least $2 \mathrm{~h}$ at RT and then washed twice with PBS and DMEM serum-free media (Gibco). Each brain slice was cultured with neonatal primary microglial cultures $\left(2.5 \times 10^{5}\right.$ cells) previously untreated or treated with MpHE $(1 \mathrm{mg} / \mathrm{mL}$ ) for $12 \mathrm{~h}$ or $100 \mu \mathrm{M}$ of GW9662 (Sigma Aldrich) for $1 \mathrm{~h}$ in FBS-free DMEM medium. After $12 \mathrm{~h}$, the cells were washed and the medium was replaced by DMEM containing 5\% FBS and 20\% L929 supernatant for $24 \mathrm{~h}$ at $37^{\circ} \mathrm{C}$ with $5 \% \mathrm{CO}_{2}$. Sections were then washed twice with PBS and fixed with 4\% PFA for subsequent histology. The brain slices were stained with Thioflavin-S and the plaque's number and size were quantified.

\section{In vivo phagocytosis assay}

Male 5XFAD mice and male Wt littermates were used (C57BL/SJL genetic background). Transgenic and Wt mice (8 weeks old) received $50 \mathrm{mg} / \mathrm{kg} /$ day of the MpHE or water (vehicle) intragastrically during 2 months. Then, mice were intraperitoneally injected with the PPARY inhibitor GW9662 (5 mg/kg) or vehicle (5\% DMSO/ 95\%PBS) for the last 3 days before sacrifice. For the in vivo $A \beta$ phagocytosis assays, mice were intraperitoneally injected with $10 \mathrm{mg} / \mathrm{kg}$ methoxy-X04 (Tocris) $6 \mathrm{~h}$ before 
sacrifice. Brains were removed and cell suspension was obtained by enzymatic $(0.2 \mathrm{mg} / \mathrm{mL}$ papain $)$ and mechanical dissociation. Myelin debris was removed by centrifugation (10 min at $700 \mathrm{~g}$ ) using $30 \%$ Percoll (Sigma). The cells present in the pellet were suspended, immunolabeled for microglia specific markers using the antibody anti-CD11b (AB_389305; 1:2000) and the anti-CD36 (AB_2072639;1: 200) and analyzed by flow cytometry using a FACSCanto II (BD Biosciences). The CD36 expression analysis was done on the $\mathrm{CD}_{11 \mathrm{~b}^{+}}$cells while the methoxy-X04 staining ana-

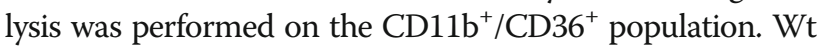
unstained and methoxy-X04 stained cells were used to determine background fluorescence and the threshold for non-phagocytic cells, respectively.

\section{PCR and $\mathrm{qPCR}$}

Total RNA was isolated from primary cultures (neonatal microglia) or from tissue (cortex) as previously described [27]. Reverse transcription was performed using M-MLV reverse transcriptase (Invitrogen, ThermoFisher Scientific) and oligo (dT) primer. Neonatal microglial cultures purity was determined by semi-quantitative PCR using the following forward $(\mathrm{F})$ and reverse $(\mathrm{R})$ primers: For F4/80: F 5'-GTG CCA TCA TTG CGG GAT TC-3' and R 5'GAC GGT TGA GCA GAC AGT GA-3', for Neurofilament-M: F 5'-GAA CCA CGA GAA GGC TCA AG-3' and R 5' - CCT CCT CTT CGT GAT TGC TC-3', for GFAP: F 5'-CAG TTC AGC TGC CAG CGC CT-3' and R 5'-GCA GAG GCA GGG CAG GAT GG-3', and for Actin: F 5'-GGG TCA GAA GGA CTC CTA TG-3' and R 5'-GGT CTC AAA CAT GAT CTG GG -3'. Quantitative real time PCR (qPCR) was carried out on ABI PRISM 7500 sequence detection system (Applied Biosystems, Foster City, CA, USA) using cDNA from Wt or 5XFAD lean or obese mice cortex treated or not treated with MpHE in combination with Maxima SYBR Green/ROX qPCR Master Mix (ThermoFisher Scientific) and specific primers. For TREM-2: F 5'-CTG GAA CCG TCA CCA TCA CTC-3', and R 5'-CGA AAC TCG ATG ACT CCT CGG-3'; for Mgl1: F 5' -TGA GAA AGG CTT TAA GAA CTG GG-3', and R 5'-GAC CAC CTG TAG TGA TGT GGG-3'; for CD86: F 5'-GAC CGT TGT GTG TGT TCT GG-3', and R 5'-GAT GAG CAG CAT CAC AAG GA-3'; for TNF: F 5' -CAG GCG GTG CCT ATG TCT C-3' ${ }^{\prime}$, and R $5^{\prime}$ - CGA TCA CCC CGA AGT TCA GTA G3'; for CD36: F 5'-GAG CAA CTG GTG GAT GGT TT3', and R 5'-GCA GCA GAA TCA AGG GAG AG-3'; for GAPDH: F 5'-GGG AAG CTC ACT GGC ATG G 3', and R 5'-CTT CTT GAT GTC ATC ATA CTT GGC AG-3'; and for Ndufa-10 (UBC): F 5'-CCG CCT TCT TCA GTA TGC AGA-3', and R 5' - TGC TTT CGG ATA TAG CCC TGG. Relative expression was calculated by normalizing to Ndufa-10 or GAPDH using the $2^{-\Delta \Delta C T}$ method [28].

\section{Western blotting}

Neonatal microglial culture homogenates were obtained by scraping with ice-cold lysis buffer (20 mM Tris pH 7.4, 137 $\mathrm{mM} \mathrm{NaCl}, 2 \mathrm{mM}$ PPiNa, $2 \mathrm{mM}$ EDTA, $1 \%$ Triton X-100, $10 \%$ glycerol, $0.5 \mathrm{mM}$ DTT, $25 \mathrm{mM} \beta$-glycerophosphate, $200 \mathrm{mM} \mathrm{Na}_{3} \mathrm{VO}_{4}, 1 \mathrm{mM}$ PMSF, and complete protease inhibitor (Roche)). Lysates were incubated $10 \mathrm{~min}$ at $4{ }^{\circ} \mathrm{C}$, then centrifuged at $14,000 \times g$ for $15 \mathrm{~min}$ at $4{ }^{\circ} \mathrm{C}$, and stored at $-70^{\circ} \mathrm{C}$ until use. Protein concentration was determined using the Bradford reagent (Bio-Rad). Total cell extracts $(20 \mu \mathrm{g})$ were resolved by SDS-PAGE and transferred onto nitrocellulose membranes (GE Healthcare). Membranes were blocked with 5\% BSA in Tris-buffer saline (TBS, 10 $\mathrm{mM}$ Tris $\mathrm{pH} 7.5,150 \mathrm{mM} \mathrm{NaCl}$ ) with $0.1 \%$ Tween-20 (Sigma) (TBS-T) and incubated with the primary antibody anti-PPAR- $\gamma$ (AB_2283990; 1:5000, Santa Cruz Biotechnology), anti-actin (AB_2223041; 1:8000, Millipore), or anti-GAPDH (AB_10622025; 1:6000, Cell Signaling) overnight at $4{ }^{\circ} \mathrm{C}$. After three washes with TBS$\mathrm{T}$, membranes were incubated with secondary antibody anti-rabbit-HRP (1:10000).

\section{ELISA}

Microglia from 8-month-old Wt and 5XFAD mice were plated onto Lab-Tek coverglass chamber wells $\left(1 \times 10^{5}\right.$ cells per well) (Nalgene Nunc International, Rochester, $\mathrm{NY)}$. After one day, cells were stimulated with $100 \mathrm{ng} /$ $\mathrm{mL}$ LPS in the presence or absence of MpHE $(1 \mathrm{mg} / \mathrm{mL})$ for $24 \mathrm{~h}$. Control cells were treated with PBS or MpHE alone. TNF and IL-6 levels were quantified from the primary microglial cultures supernatants using a commercial ELISA Kit (Biolegend, Cat. 430904 and 431304) following the manufacturer's instructions.

\section{Adipose tissue histochemistry}

Adipose tissue was fixed in 10\% paraformaldehyde and embedded in paraffin. 5- $\mu \mathrm{M}$-thick sections were prepared, deparaffinized in xylene, rehydrated in a graded ethanol series, and then stained with hematoxylin and eosin. Analysis of adipocyte histology was performed using the ImageJ software according to the manual procedure (http://rsbweb.nih.gov/ij/). Immune cells infiltration in adipose tissue was quantified by calculating the ratio of infiltration on 10 fields $(\times 40)$, of 3 slides for each individual mice, using 3 mice for each group. Light microscopic images were acquired using a Zeiss LSM510/UV Axiovert 200M confocal microscope with a Nikon COOLPIX 5000 color camera.

\section{Statistical analysis}

Results presented correspond to at least three independent experiments. No sample size calculation was performed. Data are shown as the mean \pm SEM or SD. Data were analyzed by one-way ANOVA followed by Tukey's 
post hoc test, two-way ANOVA followed by Dunnet's or Bonferroni's multiple comparison test, and three-way ANOVA followed by Tukey's multiple comparison test. Differences were considered statistically significant with a $p$ value $<0.05$. Statistical analyses were performed in Prism 7.0b or Prism 8.0 (Graphpad Software, Inc.).

\section{Results}

M. parviflora hydroalcoholic extract inhibits LPS-induced NF-KB activity in mouse RAW-Blue macrophages

Previous studies have demonstrated the anti-inflammatory and anti-oxidant effects of $M$. parviflora [21]. Therefore, we determined whether the $\mathrm{MpHE}$ negatively regulates LPS-induced NF- $\mathrm{KB}$ transcriptional activity as an indication of its anti-inflammatory activity in RAW-blue macrophage cells exposed to LPS. To this end, three different concentrations of $\mathrm{MpHE}(0.1,0.5$, and $1.0 \mathrm{mg} / \mathrm{mL})$ together with LPS $(100 \mathrm{ng} / \mathrm{mL})$ were applied to RAW-Blue cells for $12 \mathrm{~h}$. The MpHE inhibited NF-kB-driven SEAP activity by LPS in a concentration-dependent manner ( $F$ $(3,12)=28.9 ; 0.5 \mathrm{mg} / \mathrm{mL} M$. parviflora,$p<0.001$, and 1 $\mathrm{mg} / \mathrm{mL} M$. parviflora, $p<0.001$ compared with the LPS treatment and with the LPS plus $0.1 \mathrm{mg} / \mathrm{mL} M$. parviflora group) (Fig. 1a). Further, we evaluated the therapeutic potential of MpHE by pretreating the cells with LPS for 30 min and then MpHE was added for $12 \mathrm{~h}$. As for the preventive effect, $\mathrm{MpHE}$ reverted the NF- $\mathrm{kB}$-driven SEAP activity by LPS in a concentration-dependent manner ( $F$ (3, 12) $27.92 ; 0.5 \mathrm{mg} / \mathrm{mL} M$. parviflora, $p<0.001$ and $1 \mathrm{mg} /$ $\mathrm{mL} M$. parviflora, $p<0.001$ compared with the LPS treatment and with the LPS plus $0.1 \mathrm{mg} / \mathrm{mL}$ M. parviflora group) (Fig. 1b). Similarly, cell exposure to MpHE first and after $30 \mathrm{~min}$ to LPS, exhibited a clear inhibition of NF- $\kappa B$-driven SEAP activity by LPS in a concentrationdependent manner $(F(3,12) 27.92 ; 0.5 \mathrm{mg} / \mathrm{mL} M$. parviflora, $p<0.001$ and $1 \mathrm{mg} / \mathrm{mL} M$. parviflora, $p<0.001$ compared with the LPS treatment and with the LPS plus $0.1 \mathrm{mg} / \mathrm{mL} M$. parviflora group) (Fig. 1b). Importantly, under these experimental conditions, no changes in cell viability or morphology were observed (Fig. 1c, d). Altogether these data confirm the anti-inflammatory effect of the MpHE without cytotoxic effect.

\section{M. parviflora hydroalcoholic extract improves glucose homeostasis in 5XFAD mice fed with a high fat diet}

Given that alteration in glucose homeostasis resulting from obesity exacerbates A $\beta$-induced memory loss [29] and that chronic inflammation is key for AD development [30], we evaluated whether long-term administration (8 months) of the MpHE could attenuate the effects of an altered glucose metabolism on the development of the pathological changes associated with AD (Fig. 2a). The MpHE concentration used for the in vivo experiments was chosen based on our studies where increasing concentrations $(25,50$ and $100 \mathrm{mg} / \mathrm{Kg}$ ) of $\mathrm{MpHE}$ protected from learning and memory deficit in a LPSmediated neuroinflammation mouse model (Additional file 1: Figure S1). Since the three concentrations tested under our experimental conditions were equally protective we administrated $50 \mathrm{mg} / \mathrm{kg} /$ day of the $\mathrm{MpHE}$ to the 5XFAD transgenic and Wt mice, to ensure an effect and to avoid possible side effects on the animal health by the long-term administration of the higher dose. First, we evaluated glucose metabolism in obese 5XFAD mice. From the fifth week after HFD administration, the 5XFAD mice increased significantly $(p=0.0238)$ their body weight compared to 5XFAD mice fed with ND, reaching the maximum difference $(p<0.001)$ from week 15 onwards (Fig. $2 b)$. After 7 months, the glucose baseline in the 5XFAD mice fed with HFD was approximately $375 \mathrm{mg} / \mathrm{dL}$ while in the mice fed with ND was $176.8 \mathrm{mg} / \mathrm{dL}(p<0.001)$ (Fig. $2 c)$. Consistent with this, glucose tolerance was significantly impaired in obese 5XFAD mice. At 15, 30, 60, or $120 \mathrm{~min}$ after glucose load, blood glucose levels in the HFD group were 1.6, 1.8, 1.9, or 1.8 times higher than the glucose levels in the 5XFAD mice fed with ND (Fig. 2d, upper panel). Similarly, the AUC value for the HFD-fed 5XFAD mice was significantly higher than those fed with ND $(p<0.001)$ (Fig. 2d, lower panel). In accordance with this, the insulin sensitivity was decreased in the 5XFAD mice consuming HFD (Fig. 2e). At 15 min after insulin administration, blood glucose levels decreased by $25 \%$ in ND-fed group and only by $11 \%$ in HFD-fed group, as compared to glucose levels before insulin injections. At $30 \mathrm{~min}$ after insulin administration, the blood glucose levels were decreased by $45 \%$ in ND-fed 5XFAD mice and by $17 \%$ in HFD-fed group (Fig. 2e, upper panel). The AUC value for the HFD-fed 5XFAD mice was significantly higher $(p<0.001)$ than those 5XFAD mice fed with the ND (Fig. 2e, lower panel). These results confirm that 5XFAD mice fed with the HFD present insulin resistance and glucose intolerance. In parallel, HFD was administered to wild type mice for 8 months. As expected, glucose intolerance $(p=0.009)$ and insulin resistance $(p=0.0182)$ were observed in response to HFD administration in the wild type animals compared with those ND-fed wild type mice. Significant difference in the gain body weight was observed from week $22(p=0.0236)$. Furthermore, MpHE treatment improved glucose tolerance $(p=0.0268)$ and insulin sensitivity $(p=0.0045)$ in the wild type mice fed with the HFD (Fig. 2d, e). While in wild type mice fed with the ND, the MpHE had a marginal effect on glucose tolerance and insulin sensitivity.

The treatment with the MpHE delayed the increase in body weight in the 5XFAD animals fed with HFD observing significant difference since the seventh week ( $p=$ 0.0267 ) between both groups (Fig. 2b). Accordingly, with previously published data indicating that $M$. parviflora 


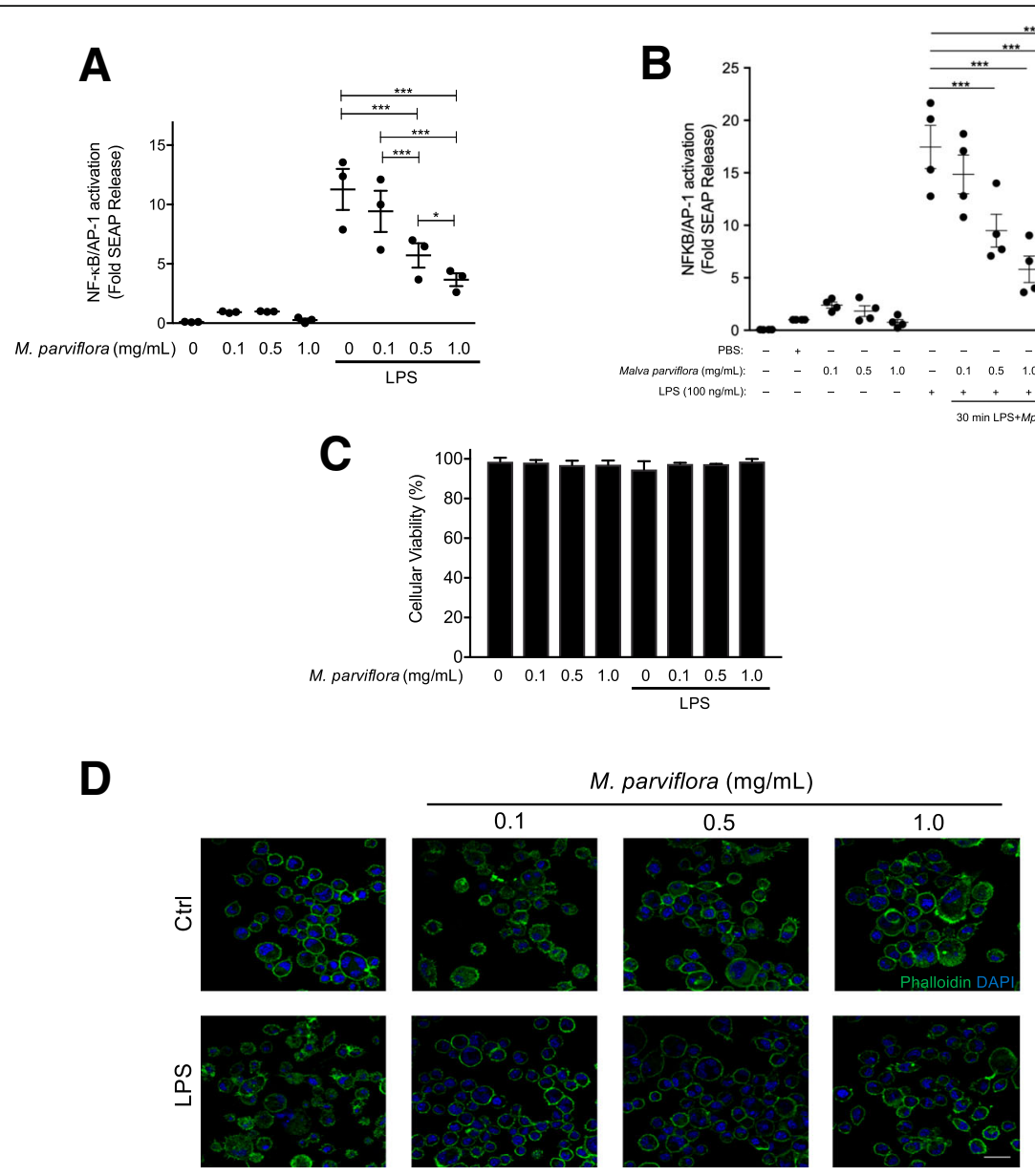

Fig. 1 The Malva parviflora hydroalcoholic extract inhibits LPS-induced NF-KB activity in mouse RAW-Blue macrophages. a RAW-Blue macrophages were untreated or treated with LPS $(100 \mathrm{ng} / \mathrm{mL})$ in the presence of the indicated concentrations of M. parviflora hydroalcoholic extract (HE) and $12 \mathrm{~h}$ later embryonic alkaline phosphatase (SEAP) activity (driven by NF-KB/AP-1 activation) was determined in the supernatants as described in the "Methods" section. Values are expressed as fold increase relative to SEAP reporter activity in untreated control cells. b RAWBlue macrophages were pre-treated with LPS or M. parviflora for $30 \mathrm{~min}$ and $12 \mathrm{~h}$ later embryonic alkaline phosphatase (SEAP) activity (driven by NF-KB/AP-1 activation) was determined in the supernatants as described in the "Methods" section. Data are shown as mean \pm SEM. Statistical analysis was performed by two-way ANOVA with repeated measures followed by post hoc Sidak's multiple comparisons test. This analysis revealed a significant effect for the MpHE concentration $F(3,12)=28.9, p<0.001$; for the LPS administration $F(1,4)=31.49 p=0.005$ and for the $M$. parviflora and LPS interaction $F(3,12)=30.88, p<0.001$. $\left.{ }^{* *} p<0.001,{ }^{*} p=0.03\right)$. c Cellular viability of RAW-Blue macrophages was evaluated using trypan blue exclusion after exposure to the $\mathrm{MpHE}$ at three different concentrations $(0.1,0.5$, and $1.0 \mathrm{mg} / \mathrm{mL})$ for $12 \mathrm{~h}$ in presence or absence of LPS $(100 \mathrm{ng} / \mathrm{mL})$. d RAW-Blue cells were treated with the indicated amount of the M. parviflora in the absence (Ctrl) or in the presence of LPS $(100 \mathrm{ng} / \mathrm{mL})$ for $12 \mathrm{~h}$. Cells were fixed and stained with phalloidin and DAPI for F-actin (green) and nuclei (blue) detection, respectively. Images were captured using the Olympus FluoView 1000 confocal multiphoton microscope (Scale bar, $30 \mu \mathrm{m}$ )

regulates glucose metabolism in a type 1 diabetes animal model [20], no significant differences were observed between animals fed with HFD $+M$. parviflora extract respect to ND-fed animals at all time points assayed $(p=$ 0.4719 at the week 28) (Fig. 2b). After eight months of HFD feeding and MpHE treatment, the glucose baseline levels (Fig. 2c), the glucose tolerance (Fig. 2d), and insulin sensitivity (Fig. 2e) were similar to those transgenic mice fed with ND. Moreover, in the case of insulin resistance test, the AUC value obtained in HFD transgenic mice treated with MpHE was twofold lower than in the HFD transgenic group without treatment $(p<0.001)$ (Fig. 2e, lower panel). These results showed that MpHE prevented the systemic insulin resistance and glucose intolerance produced by HFD in the 5XFAD mice.

\section{M. parviflora hydroalcoholic extract reduces amyloidosis} and astrogliosis in the 5XFAD mice fed with a high fat diet To determine whether MpHA attenuates the negative effects of altered glucose metabolism resulting from obesity on memory loss induced by $A \beta$ accumulation, first, we evaluated the accumulation of extracellular amyloid plaques in the hippocampus, a hallmark in the AD pathology (Fig. 3a). Amyloid plaques were significantly increased in 
A

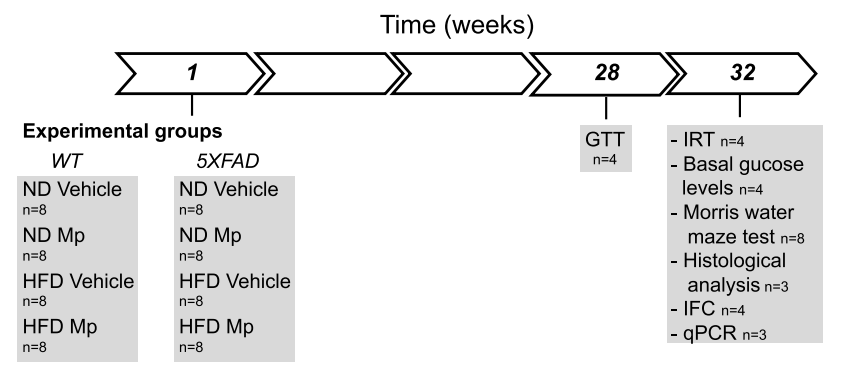

B

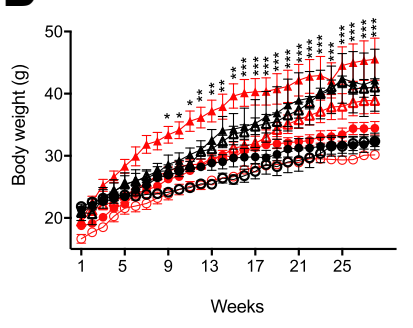

D

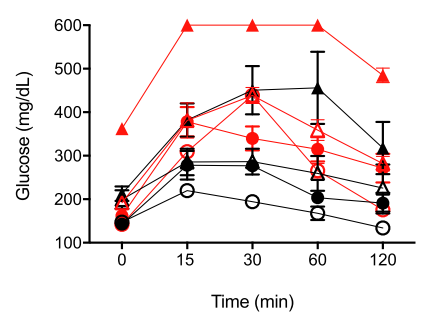

GTT

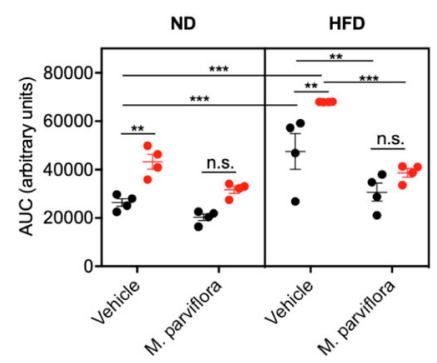

C

$\rightarrow$ WT DN

$\because$ Wt DN MP

\pm WE HFD

$\triangle$ Wt HFD MP

$\because$ 5XFAD ND

$\because 5$ XFAD ND MP

$-5 X F A D N D M P$
$-5 X F A D ~ H F D$

$\triangle 5$ XFAD HFD Mp

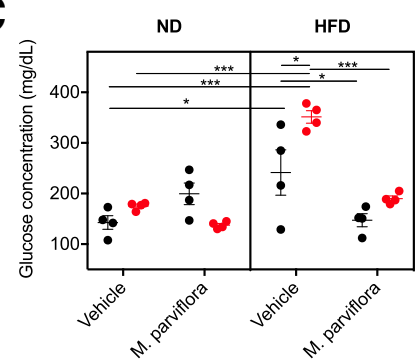

E
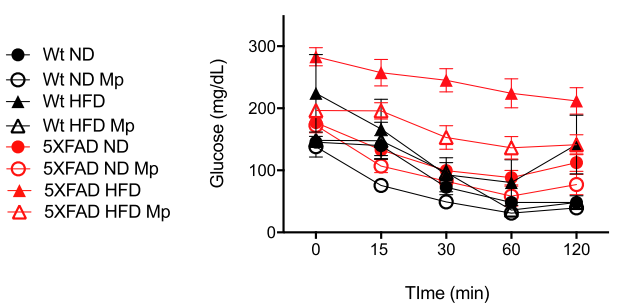

IRT

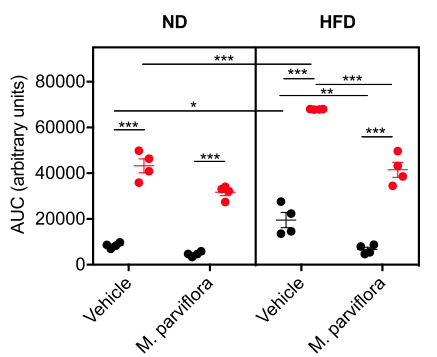

- Wt

- 5XFAD
- Wt

- 5XFAD
- Wt

5XFAD 
(See figure on previous page.)

Fig. 2 Malva parviflora hydroalcoholic extract promotes insulin sensitivity and glucose tolerance in 5XFAD transgenic mice fed with high-fat diet. a Graphical time line of the study design and experimental procedures. GT, glucose tolerance test; IRT, insulin resistant test; IFC,

immunofluorescence. b Body weight gain (g) was measured weekly during 28 weeks in wild type (Wt) mice fed with normal diet (ND; closed black circle) or high-fat diet (HFD; closed black triangle) and those that received intragastrically water or $50 \mathrm{mg} / \mathrm{kg} / \mathrm{day}$ of the $\mathrm{MpHE}$ (Mp): Wt $\mathrm{ND}+\mathrm{Mp}$ (open black circle) or Wt HFD + Mp (open black triangle), or transgenic 5XFAD mice fed with a normal diet (ND; closed red circle) or a high-fat diet (HFD; closed red triangle) that received intragastrically water or $50 \mathrm{mg} / \mathrm{kg} /$ day of the MpHE (Mp): 5XFAD ND + Mp (open red circle), or $5 \mathrm{XFAD}$ HFD $+\mathrm{Mp}$ (open red triangle). Data are shown as mean $\pm \mathrm{SEM}, n=4$ in Wt ND, $n=4$ in Wt HFD, $n=4$ in Wt ND $+\mathrm{Mp}, n=4$ in Wt HFD + Mp, $n=10$ in 5XFAD ND, $n=10$ in 5XFAD HDF, $n=10$ in 5XFAD ND + Mp and $n=9$ in 5XFAD HFD + Mp. Statistical analysis was performed by two-way ANOVA with repeated measures followed by post hoc Bonferroni's multiple comparisons test. This analysis revealed a significant effect for the genotype $F(7,47)=9.971, p<0.001$; for the time $F(27,1269)=206.5 p<0.001$ and for the genotype and time interaction $F(189,1269), p<0.001$. (* $p=0.0488,{ }^{* *} p=0.0069$, *** $\left.p<0.001\right)$. c Basal blood glucose concentrations in Wt or transgenic 5XFAD mice after 8 months of being fed with ND or HFD alone or treated with Mp. Data are shown as mean \pm SEM, $n=4$ for all the groups. Statistical analysis was performed by three-way ANOVA followed by Tukey's multiple comparisons test. This analysis revealed a significant effect for the genotype $F(1,24)=5.029, p=0.03440$; for the diet $F(1,24)=25.08, p<0.001$; for the $M$. parviflora treatment $F(1,24)=18.56 ; p=0.002 ;$ for the genotype and diet interaction $F(1,24)=11, p=0.0029$; for the $M$. parviflora treatment and diet interaction $F(1,24)=24.99, p<0.001$; for the genotype and $M$. parviflora treatment interaction $F(1,24)=8.661 p=0.0071$; and for the genotype, $M$. parviflora treatment, and diet interaction $F(1,24)=0.2458, p=0.6245$. $\mathbf{d}$ Blood glucose during intraperitoneal glucose tolerance test (GTT) of Wt or transgenic 5XFAD mice 8 months after of being fed with ND or HFD alone or treated with M. parviflora (Mp). Bar graph (lower panel) represents the area under the curve (AUC). Data are shown as mean \pm SEM, $n=4$ for all the groups. Statistical analysis was performed by three-way ANOVA followed by Tukey's multiple comparisons test. This analysis revealed a significant effect for the genotype $F(1,24)=36.52, p<0.001$; for the diet $F(1,24)=45.37, p<0.001$; for the $M$. parviflora treatment $F(1,24)=46.23, p<$ 0.001 ; for the genotype and diet interaction $F(1,24)=0.0002756, p=0.9869$; for the $M$. parviflora treatment and diet interaction $F(1,24)=9.277, p=$ 0.0056; for the genotype and M. parviflora treatment interaction $F(1,24)=3.678 p=0.0671$; and for the genotype, $M$. parviflora treatment, and diet interaction $F(1,24)=0.5456, p=0.4673$. e Blood glucose levels were measured at several time points following insulin administration during the insulin resistance test (IRT) of Wt or transgenic 5XFAD mice 8 months after of being fed with ND or HFD alone or treated with M. parviflora (Mp). Bar graph (lower panel) represents the area under the curve (AUC). Statistical analysis was performed by three-way ANOVA followed by Tukey's multiple comparisons test. This analysis revealed a significant effect for the genotype $F(1,24)=356.6, p<0.001$; for the diet $F(1,24)=38.47, p<$ 0.001 ; for the M. parviflora treatment $F(1,24)=36.14, p<0.001$; for the genotype and diet interaction $F(1,24)=7.772, p=0.0102$; for the $M$. parviflora treatment and diet interaction $F(1,24)=4.078, p=0.0547$; for the genotype and $M$. parviflora treatment interaction $F(1,24)=15.14 p=0.007$; and for the genotype, M. parviflora treatment, and diet interaction $F(1,24)=3.468, p=0.0749$

the 5XFAD mice after 8 months of HFD feeding compared with 5XFAD mice fed with the ND $(p<0.0029)$ (Fig. 3a, right panel). As reported [31], this result confirms that HFD aggravates the AD pathology. However, long-term administration of $\mathrm{MpHE}$ reduced $\mathrm{A} \beta$ accumulation throughout hippocampus of 5XFAD mice fed either with ND $(p=0.0028)$ or with HFD $(p<0.001)$ compared to the $\mathrm{A} \beta$ levels observed in animals administered with the vehicle (Fig. 3a, right panel).

Astrocyte activation (astrogliosis) in response to $\mathrm{A} \beta$ accumulation is a characteristic of AD development. GFAP staining of sagittal sections from 9-months-old 5XFAD mice showed that long-term treatment (8 months) with the MpHE reduced the astrogliosis throughout the hippocampus of HFD-fed 5XFAD mice (Fig. 3b).

Together, these results point out that $\mathrm{MpHE}$ attenuates the inflammatory process in the brain triggered from $A \beta$ accumulation resulting from APP and Presenilin 1 mutations and that MpHE also attenuates the effect of altered glucose metabolism on $\beta$-amyloid plaque formation and astrogliosis.

\section{M. parviflora hydroalcoholic extract ameliorates impairments in spatial memory in 5XFAD mice fed with a high fat diet}

Given that the MpHE attenuated the alterations in glucose metabolism and reduced $\mathrm{A} \beta$ deposition in 5XFAD mice fed with HFD, we tested whether this treatment could also impact spatial learning and memory. To this purpose, the Morris water maze test was performed. In the training trials, Wt mice fed with HFD took more time to find the platform than Wt mice fed with ND $(p=0.008)$ (Fig. 4a) and their path lengths were less directed to the platform (Fig. 4d). Notably, 9-month-old 5XFAD mice fed with ND present similar learning impairments when compared to Wt animals fed with HFD (Fig. 4a, b). 5XFAD animals fed with ND $(p=0.003)$ and HFD $(p=<0.001)$ showed higher escape latencies in the learning test (Fig. $4 \mathrm{~b})$ and longer times to the platform in the memory test (5XFAD ND $p=0.002$; 5XFAD HFD $p<0.002$ ) compared with Wt mice fed with ND (Fig. 4c). The HFD did not worsen memory loss in 9-month-old 5XFAD mice, since transgenic mice fed with ND or HFD had similar escape latencies to find the platform. Nonetheless, the MpHE improved spatial learning in 5XFAD mice fed with HFD because it reduced significantly the escape latency compared to untreated transgenic mice $(p=0.05)$ and the latency is even similar to that of the ND-fed Wt mice (Fig. 4b). In the probe trial assay, most of the 5XFAD mice fed with ND and treated with the MpHE, reached the quadrant where the platform was located in a shorter time than the untreated transgenic mice (Fig. 4c). The 5XFAD animals fed with HFD and treated with $M$. parviflora showed a considerable reduction of the escape latency $(p<0.001)$ 


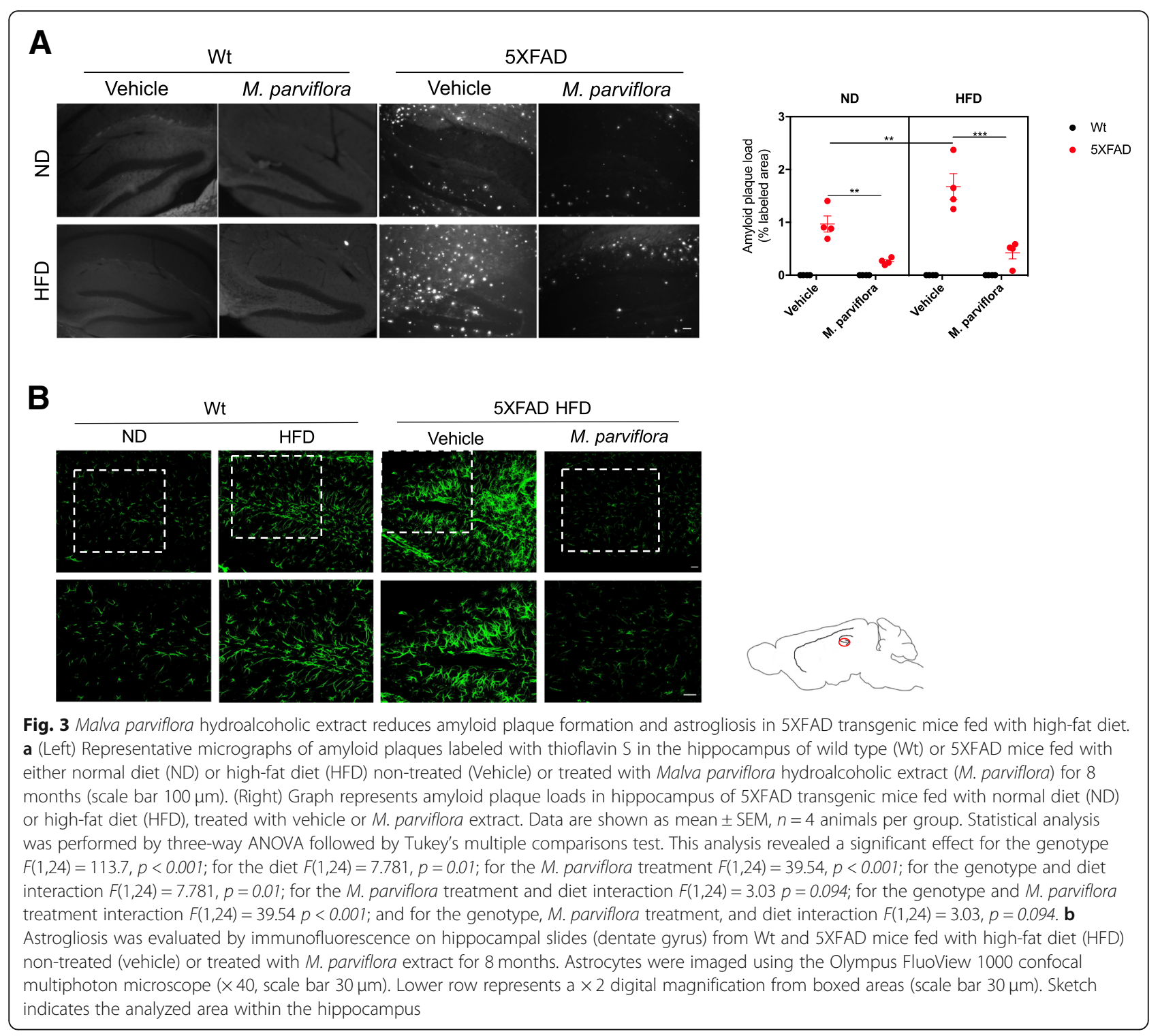

compared with that of the 5XFAD HFD group (Fig. 4c). Accordingly, independent of the diet, transgenic mice administered with MpHE showed reduced path lengths and crossed over the location of the hidden platform more frequently compared with the untreated 5XFAD mice (Fig. $4 \mathrm{~d})$. The M. parviflora capacity to ameliorate the memory impairment of 5XFAD transgenic model mice was further evident in the probe trial assay, where the latencies of the M. parviflora treated transgenic mice were very similar to that of the ND-fed Wt mice (Fig. 4c). The MpHE had no effect on the cognitive capacities of Wt mice fed with a ND; however, Wt animals fed with HFD and treated with this extract showed a significant reduction $(p=0.04)$ in the escape latencies (Fig. 4b). Together these results indicate that the MpHE attenuates the learning and memory deficiencies resulting from $A \beta$ deposition and altered glucose metabolism.

\section{M. parviflora hydroalcoholic extract regulates microglia activation in vitro}

Many studies indicate that the microglial cells, which are crucial in the CNS homeostasis by clearing misfolded proteins and controlling inflammation, have altered functions in the $\mathrm{AD}$ [32]. As first approach to determine whether MpHE could modulate microglia activation and thus attenuate memory loss in the 5XFAD mice, microglia primary cultures were prepared from brain of neonatal mice. Microglia isolation was determined by confocal microscopy (Fig. 5a), flow cytometry (Fig. 5b), and RT-PCR (Fig. 5c) assays using different cell markers, including F4/80 and CD11b (microglia), GFAP (astrocytes), and Neurofilament $M$ (neurons). Purified microglia was evidenced by the expression of F4/80 and CD11b (Fig. 5a-c). Using these cultures, we evaluated the effect of the MpHE on LPS-induced microglia activation. Phalloidin staining 


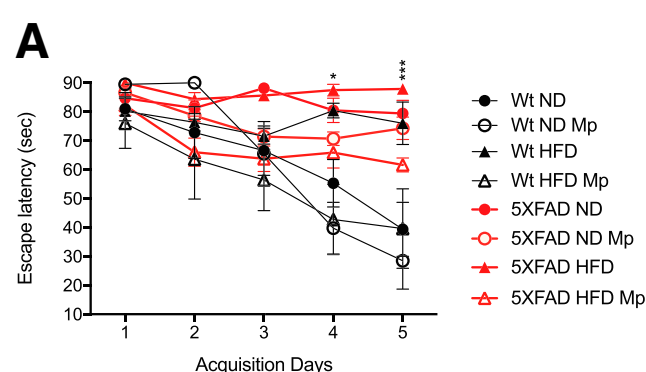

D

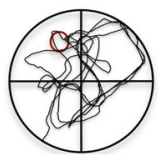

Wt ND

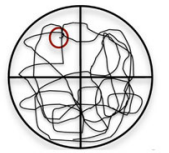

Wt HFD

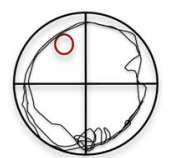

5XFAD ND

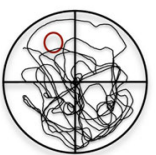

- 5XFAD

- Wt

- 5XFAD

5XFAD HFD

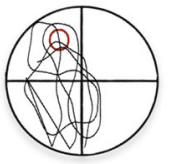

Wt ND Mp

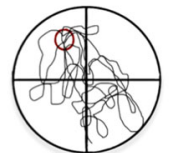

Wt HFD Mp

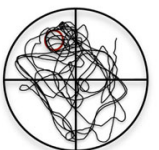

5XFAD ND Mp

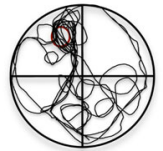

5XFAD HFD Mp

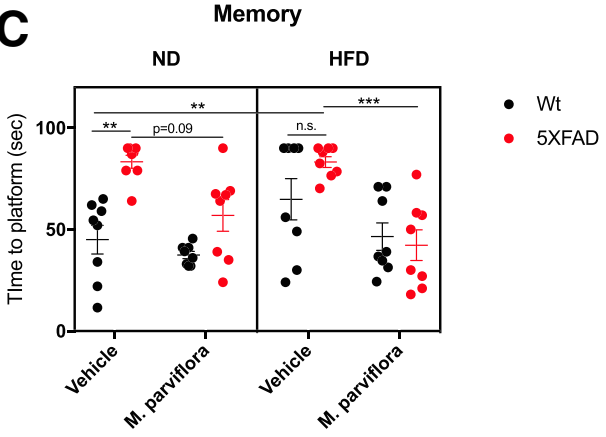

Fig. 4 Malva parviflora hydroalcoholic extract protects 5XFAD transgenic mice from memory deficit. Morris Water Maze test was performed to evaluate spatial memory in 5XFAD mice treated with Malva parviflora hydroalcoholic extract (M. parviflora). a Time (sec) need to reach the hidden platform (escape latency) during the five acquisition days (test trial) of wild type (Wt) mice fed with normal diet (ND) (closed black cirle) or highfat diet (HFD) (closed black triangle) and those that received intragastrically water or $50 \mathrm{mg} / \mathrm{kg} /$ day of the MpHE (Mp): Wt ND + Mp (open black circle) or Wt HFD + Mp (open black triangle), or transgenic 5XFAD mice fed with a normal diet (ND) (closed red circle) or a high-fat diet (HFD) (closed red triangle) that received intragastrically water or $50 \mathrm{mg} / \mathrm{kg} /$ day of the MpHE (Mp): 5XFAD ND + Mp (open red circle), or 5XFAD HFD + $\mathrm{Mp}$ (open red triangle). Data are shown as mean $\pm \mathrm{SEM}, n=8$ animals per group. Statistical analysis was performed by two-way ANOVA followed by Sidak's multiple comparisons test. This revealed a significant effect for time $F(4,108)=12.16, p<0.0001$, Genotype $F(7,27)=11.17, p<0.0001$ and for the interaction between time and genotype $F(28,108)=1.969, p=0.007$ (day 4 Wt ND vs 5 XFAD HFD * $p=0.04$; day 5 Wt ND vs 5 XFAD HFD ${ }^{* * *} p<0.0001$ ). $\mathbf{b}$ Area under the curve (AUC) of the latencies for each group was calculated using the trapezoidal rule. Data are shown as mean \pm SEM, $n=8$ animals per group. Statistical analysis was performed by three-way ANOVA followed by Tukey's multiple comparisons test. This analysis revealed a significant effect for the genotype $F(1,56)=14.95, p<0.001$; for the $M$. parviflora treatment $F(1,56)=15.69, p<0.001$; for the genotype and diet interaction $F(1,56)=1.401, p=0.24$; for the $M$. parviflora treatment and diet interaction $F(1,56)=5.734, p=0.02$; for the genotype and $M$. parviflora treatment interaction $F(1,56)=2.328, p=0.13$; for the genotype, $M$. parviflora treatment and diet interaction $F(1,56)=$ $2.467, p=0.12$. c Time (seconds; sec) to platform for each group during the probe trial (day eight) in the absence of platform. Statistical analysis was performed by three-way ANOVA followed by Tukey's multiple comparisons test. This analysis revealed a significant effect for the genotype $F(1,56)=15.46, p<0.001$; for the M. parviflora treatment $F(1,56)=25.97, p<0.001$; for diet $F(1,56)=0.5947, p=0.44$; for the genotype and diet interaction $F(1,56)=5.703, p=0.02$; for the $M$. parviflora treatment and diet interaction $F(1,56)=1.915, p=0.17$; for the genotype and $M$. parviflora treatment interaction $F(1,56)=5.131, p=0.03$; for the genotype, M. parviflora treatment and diet interaction $F(1,56)=0.04011, p=0.84$. $\mathbf{d}$ Representative swimming paths of mice during the probe trial on day eight are depicted. The hidden platform was located on the NW quadrant

revealed that LPS treatment induced microglia morphological changes by increasing the amoeboid "activated" morphology $(F(3,24)=20.49, p<0.001)$ and reducing the ramified morphology $(F(3,24)=7.526, p<0.01)$ as compared with the control cells (Fig. $5 \mathrm{~d}$, e). In contrast, when $\mathrm{MpHE}$ was added to the microglial cultures, the LPS- 


\section{A}
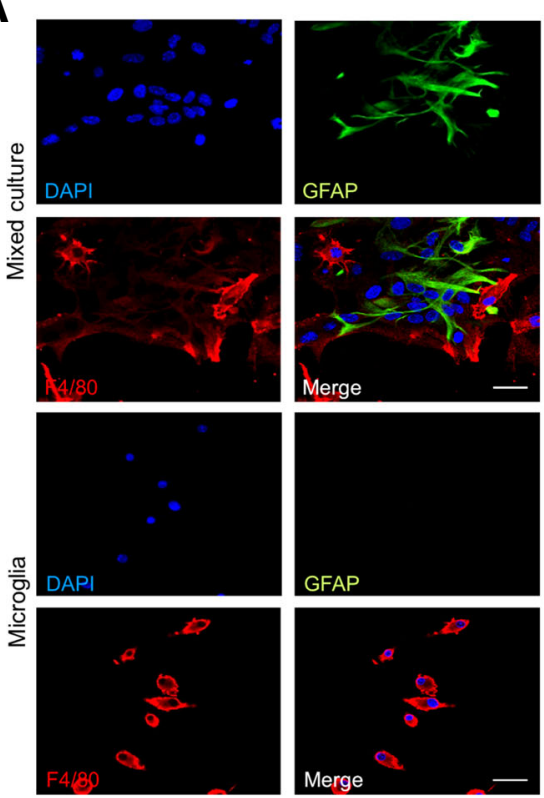

D

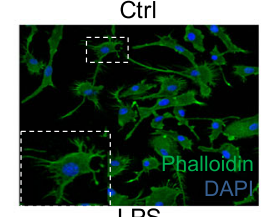

LPS

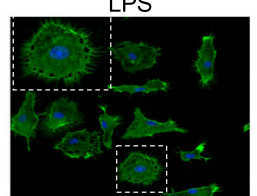

M. parviflora
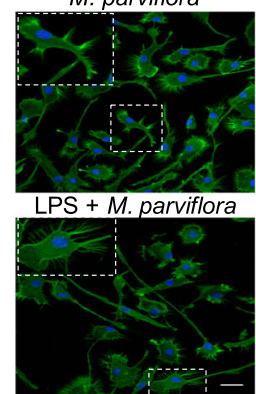

LPS + M. parviflora
B
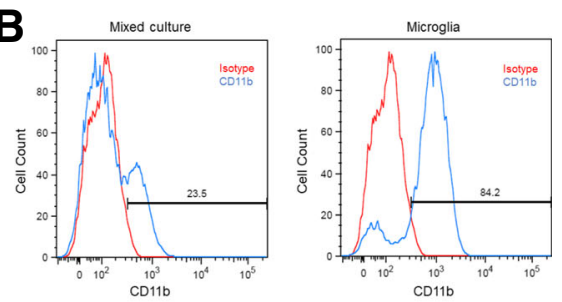

C

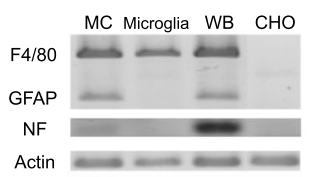

E

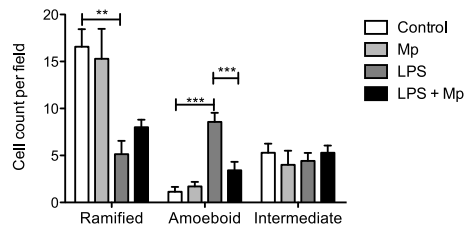

$\mathbf{F}$

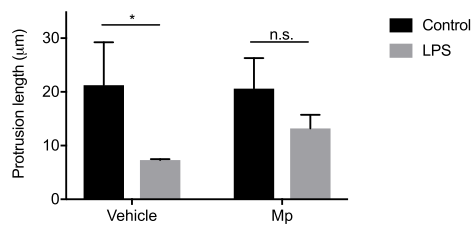

G

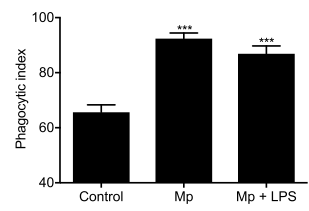

Fig. 5 Malva parviflora hydroalcoholic extract regulates LPS-induced microglia activation. Microglia primary cultures were isolated from neonatal wild type animals as described in the "Methods" section. Microglia enrichment was determined as follows. a Confocal microscopy was used to examine GFAP (astrocytes) and F4/80 (microglia) expression in mixed cultures and after microglia purification (Microglia). Nuclei were visualized by DAPI staining (scale bar, $30 \mu \mathrm{m}$ ). b Microglia enrichment was determined by flow citometry using anti-CD11b antibodies. c The mRNA levels of different cell markers, microglia (F4/80); astrocytes (GFAP) and neurons (Neurofilament M; NF) were determined in the mixed cultures (MC), isolated microglia (microglia), whole brain (WB) and CHO cells by RT-PCR analysis as described in the "Methods" section. Actin levels were used as internal control. d Microglial cultures were exposed to PBS (Ctrl), LPS (100 ng/mL), MpHE (M. parviflora) (1 mg/mL) or LPS (100 ng/mL) and MpHE $(1 \mathrm{mg} / \mathrm{mL})(L P S+M$. parviflora) for $24 \mathrm{~h}$. Cells were fixed, stained with phalloidin and DAPI for F-actin (green) and nuclei (blue) detection, respectively. Microglia was imaged using the Olympus FluoView 1000 confocal multiphoton microscope (scale bar, $30 \mu \mathrm{m}$ ). The boxed areas were $\times 2$ digitally magnified and shown as inset. e The microglia morphologies were classified as ramified, amoeboid and intermediate shapes in the different groups described in (D); MpHE (Mp). One hundred cells were measured for each experimental condition. Data (mean \pm SEM) were analyzed by one-way ANOVA followed by Tukey's post hoc test $\left({ }^{* *} p<0.01 ;{ }^{* * *} p<0.001\right)$. f Microglial cultures were exposed to PBS (Control) or LPS $(100 \mathrm{ng} / \mathrm{mL})$ in the presence or absence Vehicle) of MpHE $(1 \mathrm{mg} / \mathrm{mL})(M p)$ for $24 \mathrm{~h}$. The length of the protrusions ( $\mu \mathrm{m})$ of the microglia were determined using Neurite Tracer from ImageJ software (National Institutes of Health, Bethesda, MD). Data (mean \pm SEM) were analyzed by two-way ANOVA followed by post hoc Bonferroni's multiple comparisons test. This analysis revealed a significant effect for the LPS F(1,8)=13.32, $p=0.006$; not for the treatment with M. parviflora $F(1,8)=0.8054 p=0.40$ or for the LPS and M. parviflora interaction $F(1,8)=1.245 p=0.30$. $\mathbf{g}$ Microglial cultures were exposed to PBS (Control), MpHE (1 mg/mL) (Mp) or LPS (100 ng/mL) and MpHE (1 mg/mL) (LPS + Mp) for $24 \mathrm{~h}$. The phagocytic index was calculated by multiplying the percentage of microglia with internalized latex beads by the average number of internalized latex beads per each group. Data were collected from seven random fields per group and analyzed by one-way ANOVA followed by Tukey's post hoc test $\left({ }^{* * *} p<0.001\right.$ vs control)

induced amoeboid morphological changes were significantly reduced $(F(3,24)=20.49, p<0.001)$ (Fig. 5 d, e). In the same way, LPS treatment reduced the protrusion length of the microglia processes $(p=0.0195)$ compared with control microglial cells that had fine processes towards the trailing end (Fig. 5f). The MpHE treatment prevented the reduction in the protrusion length resulting from LPS exposure (Fig. 5f). Even more, LPS-treated 
microglia exposed to MpHE showed enhanced phagocytic activity when compared to untreated control cells $(F(2$, $15)=30.67, p<0.001$ ) (Fig. 5g). Interestingly, M. parviflora treated microglia showed increased phagocytic activity similar to that observed in microglial cells treated with LPS and M. parviflora $(F(2,15)=30.67, p<0.001$ ) (Fig. 5g) . Together, these results indicate that the MpHE modulates microglia activation in response to inflammatory stimuli while promoting its phagocytic activity.

\section{M. parviflora hydroalcoholic extract stimulates the microglia phagocytic activity from 5XFAD mice}

Taking into consideration that the inflammatory environment induced by $\mathrm{A} \beta$-accumulation skews microglia to an inflammatory phenotype impairing its phagocytic capacity $[33,34]$ thus leading to the AD progression and that $\mathrm{MpHE}$ induced the phagocytic activity of neonatal microglia in primary cultures (Fig. 5), we evaluated whether MpHE could restore the phagocytic activity of microglia from adult 5XFAD mice. For this purpose, pure primary microglial cultures from 8 - and 10-monthold Wt or 5XFAD mice were isolated (Fig. 6a) and exposed to fluorescent E. coli in the present or absence of the MpHE. Interestingly, the percentage of microglia with internalized bacteria was slightly reduced in the cultures of microglia isolated from brains with $A \beta$ deposition (5XFAD mice, 8 and 10 months old) when compared to cultures of microglia isolated from healthy brains (Wt mice) (Fig. 6b, c), thus confirming that an inflammatory environment impairs microglia phagocytic activity [9]. However, exposure to the MpHE increased the number of cells with internalized bacteria in 5XFAD microglial cultures from 8- $(F(5,12)=7.351, p<0.05)$ and 10 -month-old mice $(F(5,12)=7.351, p<0.05)$ (Fig. $6 \mathrm{~b}, \mathrm{c})$. Furthermore, the MpHE significantly increased the number of cells containing more than 10 internalized $E$. coli in both, Wt and 5XFAD microglia $(\mathrm{F}(5,294)$ $=86.56$, Wt $1-5, p<0.01$; Wt $6-10, p<0.001 ; 5 X F A D ~ 8-$ month-old 1-5, $p<0.001$; 5XFAD 8 -month-old 6-10, $p<0.001$; 5XFAD 10-month-old 1-5, $p<0.01$; 5XFAD 10-month-old 6-10, $p<0.001$ ) (Fig. 6d). Additionally, the phagocytic index was increased for the presence of $\mathrm{MpHE}$ in all the cases $(F(5,12)=620, p<0.001$ for all the cases) (Fig. 6e). Thus, our results indicate that the negative effect of the MpHE on $\mathrm{A} \beta$ plaques formation may result from improved microglia phagocytic activity and $\mathrm{A} \beta$ peptide clearance.

\section{M. parviflora hydroalcoholic extract reduces the M1 phenotype in the microglial cells from 5XFAD mice}

Previous reports showed that the microglial cells in the presence of $A \beta$ plaques exhibit morphological and molecular changes, their soma and the thickness processes are increased [35] as well as the expression of inflammatory mediators a characteristic of an activated M1 phenotype that result in neurotoxicity [36]. Hence, we evaluated if the MpHE could also modulate these alterations. We used Iba1 as specific marker to analyze the microglia morphological changes in cortex and hippocampus of 5XFAD mice untreated or treated (8 months) with the MpHE. In contrast to the activated microglia (amoeboid) observed in untreated 5XFAD mice, the presence of ramified microglia with long and thin processes within the cortex and hippocampus of 5XFAD mice exposed to MpHE was evident (Fig. 7a, b). Importantly, an increased microglia accumulation around the $A \beta$ plaques was observed in the cortex and hippocampus of 5XFAD mice treated with the MpHE as determined by the Manders's coefficient (hippocampus 5XFAD mice $0.774 \pm 0.105$ vs 5XFAD mice treated with $M$. parviflora $0.875 \pm 0.084$; cortex 5 XFAD mice $0.674 \pm 0.076$ vs 5XFAD mice treated with $M$. parviflora $0.894 \pm 0.035$ ) (Fig. 7a, b). This correlated with reduced thioflavin-S staining intensity (Fig. 3a), suggesting improved $A \beta$ plaques degradation. Moreover, the increased mRNA levels of proinflammatory markers as CD86 (Wt ND vs 5XFAD ND $p<0.001$; Wt HFD $v s$ XXFAD HFD $p=0.0045$ ), which is expressed by the microglial cells in the brain [37], and TNF [38] (Wt ND vs 5XFAD ND, $p<0.001$ ) observed in the cortex of 5XFAD mice independent of the diet were reduced in the cortex from 5XFAD mice treated with MpHE (CD86: 5XFAD ND vs 5XFAD ND $M$. parviflora $(p<$ 0.001 ) and 5XFAD HFD vs 5XFAD HFD $M$. parviflora $(p=0.0167)$ (Fig. 8a); TNF: 5XFAD ND vs 5XFAD ND treated with $M$. parviflora, $p<0.001$; 5XFAD HFD vs 5XFAD HFD treated with $M$. parviflora, $p=0.02$ ) (Fig. 8b). In contrast, the levels of Mgl1 (macrophage galactose-type lectin-1), an anti-inflammatory microglia marker [39], showed a mild increase in the presence of the extract in the 5XFAD fed with a ND or HFD (Fig. 8c). Also, we analyzed the mRNA levels of TREM-2 (triggering receptor expressed on myeloid cells-2), a phagocytosis specific marker in microglial cells [40]. We found that TREM-2 levels were increased in the cortex from 5XFAD mice and the M. parviflora extract treatment slightly further increased TREM-2 levels in lean and obese mice (Fig. 8d).

To further corroborate the anti-inflammatory effect of $\mathrm{MpHE}$, primary microglial cultures from 5XFAD mice (8 months) were treated con LPS $(100 \mathrm{ng} / \mathrm{mL})$ in the absence or presence of MpHE $(1 \mathrm{mg} / \mathrm{mL})$ for $24 \mathrm{~h}$. Interestingly, although LPS promoted higher production of both TNF and IL-6 in microglia from the 5XFAD mice than that from wild type mice, the increased levels of TNF and IL- 6 released to the supernatant in response to LPS (TNF: Wt Ctrl $v s$ Wt LPS $p=0.0434$; 5XFAD Ctrl vs 5XFAD LPS $p<0.0001$; Wt LPS $v s$ 5XFAD LPS $p=0.0015$; and IL-6: Wt Ctrl vs Wt LPS $p=0.0001$; 5XFAD Ctrl $v s$ 5XFAD LPS $p<0.0001$; Wt LPS $v s$ 5XFAD LPS $p<0.0001$ ) was significantly reduced in 


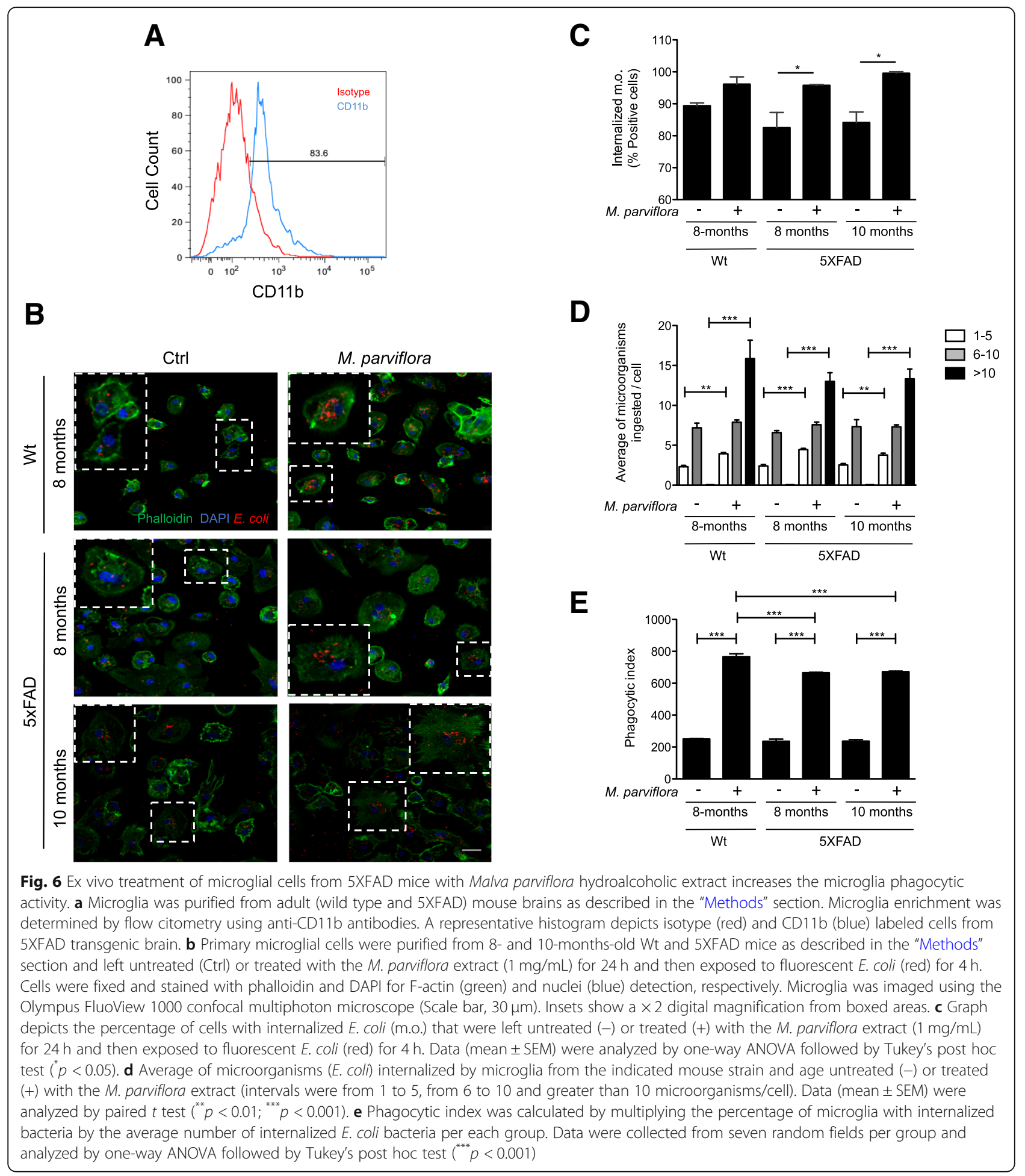

response to MpHE (TNF: 5XFAD LPS vs 5XFAD LPS treated with $M$. parviflora, $p=0.0001$; and IL-6: 5XFAD LPS vs 5XFAD LPS treated with $M$. parviflora, $p<$ 0.0001 ) (Fig. 8e, f). According with this, the in vivo treatment with the MpHE also reduced the inflammatory process in the adipose tissue of wild type and 5XFAD mice fed with the HFD, since there was a clear reduction in the infiltration of immune cells into the adipose tissue of mice fed with HFD and treated with the MpHE compared with vehicle-treated animals (Additional file 2: Figure S2). Together these results indicate that (1) by regulating microglia phagocytic activity, (2) by preventing 


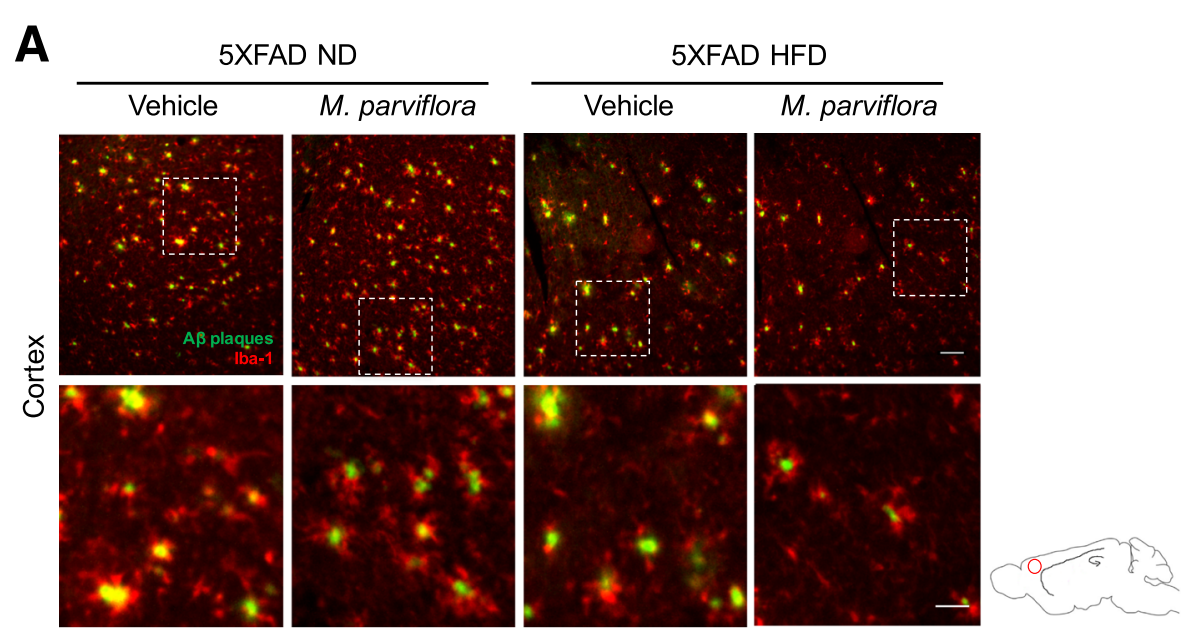

B

5XFAD ND
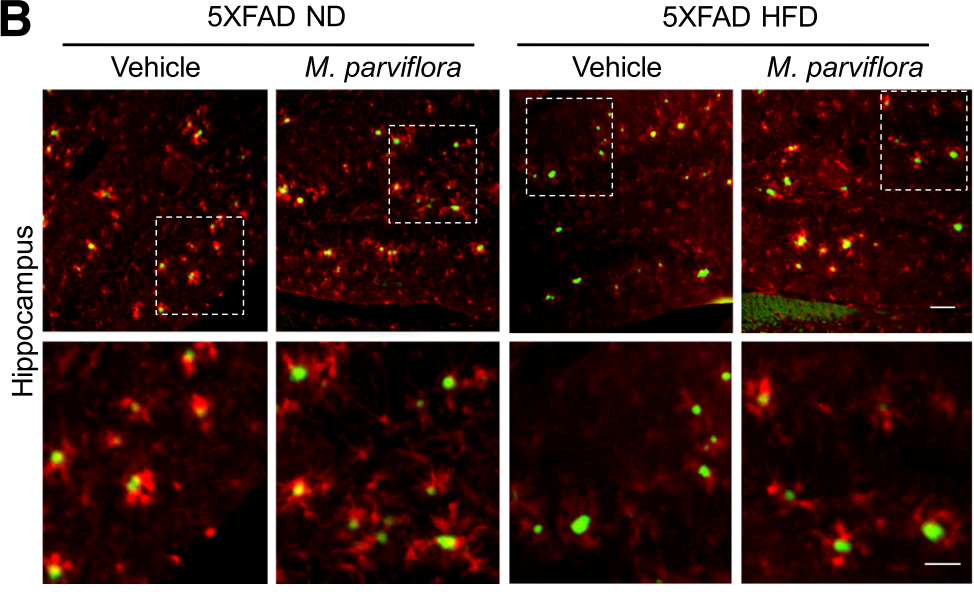

Fig. 7 Malva parviflora hydroalcoholic extract increases microglia accumulation around the A $\beta$ plaques in the cortex and hippocampus of 5XFAD mice. Amyloid plaques were labeled with thioflavin S (green) and microglia with anti-lba-1 antibodies (red) on cortical a or hippocampal sections (dentate gyrus) b from 5XFAD mice fed with either normal diet (ND) or high-fat diet (HFD) non-treated (Vehicle) or treated with M. parviflora extract (M. parviflora) for 8 months. Representative micrographs are depicted. Images were captured using the Zeiss Axioskop Observer Z1 inverted fluorescence microscope $(\times 10$, scale bar $100 \mu \mathrm{m})$. Lower row represents a $\times 3$ digital magnification from boxed areas (scale bar $30 \mu \mathrm{m})$. Sketch indicates the analyzed area within the cortex and the hippocampus, respectively

the pro-inflammatory M1 phenotype, M. parviflora reduces $\beta$-amyloid plaque load and improves learning and memory in lean and obese mice and (3) M. parviflora attenuates the inflammatory process in the adipose tissue of obese mice.

\section{Scopoletin and oleanolic acid are present in the $M$. parviflora hydroalcoholic extract}

Given that $M$. parviflora reduces neuroinflammation and regulates microglia activation in the 5XFAD mice, the fractionation and characterization of the MpHE was performed to ascertain the bioactive components. MpHE was subjected to a series of solvent extraction and the water and ethyl acetate fractions were subjected to HPLC analysis to identify compounds with potential anti-inflammatory or anti-oxidant activities. Scopoletin was identified in the ethyl acetate (AcOet) fraction (Fig. 9a). This coumarin displayed the same retention time (9.4 $\mathrm{min})$ and UV spectra $(\lambda \max =205,228,294,348$ $n \mathrm{~m})$ than the commercial reference (Fig. 9b). Oleanolic acid was also identified in the same fraction (Fig. 9a), showing the same retention time $(25.85 \mathrm{~min})$ and $\mathrm{UV}(\lambda$ $\max =192 \mathrm{~nm})$ spectra than the commercial reference (SIGMA, 95\% purity) (Fig. 9c). Additionally, the presence of two peaks in the early retention times, displayed on the UV spectra $3.95 \mathrm{~min}(\lambda=204,276,369 \mathrm{~nm})$ and $5.4 \mathrm{~min}(\lambda=200,220,279)$, is related to flavonoid compounds. Quantification of scopoletin was established with calibration curve (linear regression displayed the equation $\left.Y=84,221 X-188,219 R^{2}=0.9995\right)$ of this coumarin. Based on the obtained equation $Y=84,221 X-$ 188,219 , it is possible to establish a $1.22 \mathrm{mg}$ of scopoletin 
A

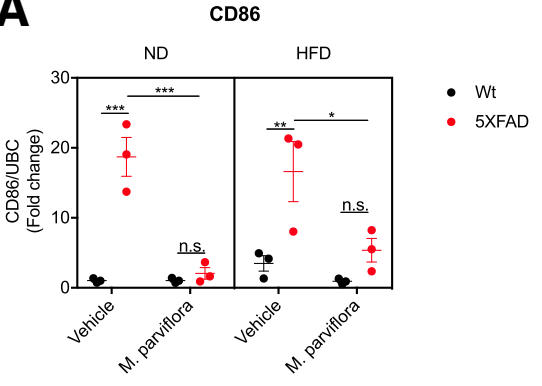

C

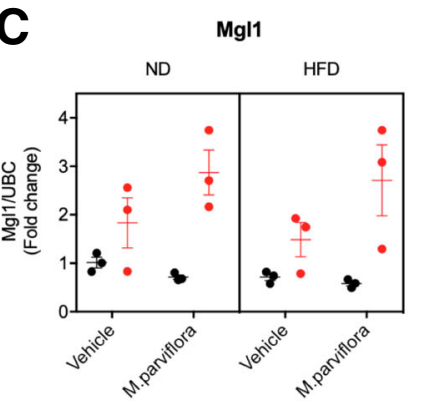

$\mathbf{E}$

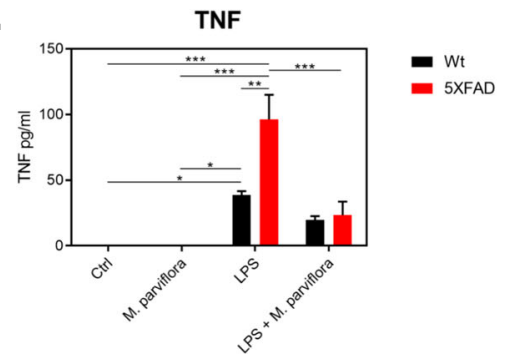

B

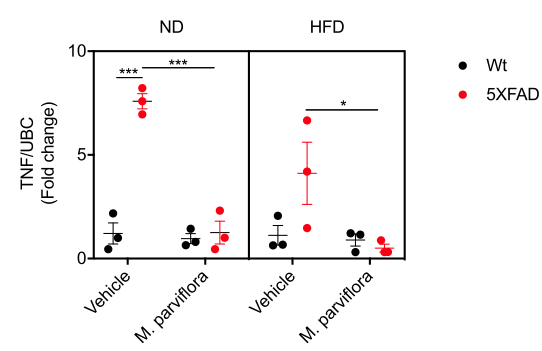

D

TREM-2

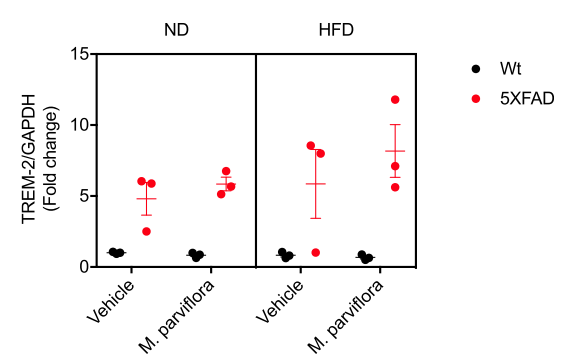

$\mathbf{F}$

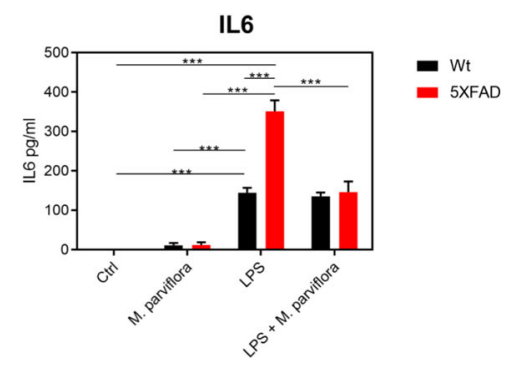

Fig. 8 Malva parviflora hydroalcoholic extract attenuates microglia pro-inflammatory M1 phenotype in the cortex of 5XFAD mice. Total RNA was isolated from the cortex of Wt or 5XFAD mice fed with either normal diet (ND) or high-fat diet (HFD) non-treated (Vehicle) or treated with MpHE (M. parviflora) for 8 months. a The transcript levels of CD86 (marker of M1 state) were determined by RT-qPCR as described in the "Methods" section. Data are shown as mean \pm SEM, $n=3$ animals per group. Statistical analysis was performed by three-way ANOVA followed by Tukey's multiple comparisons test. This analysis revealed a significant effect for the genotype $F(1,16)=42.45, p<0.001$; for the diet $F(1,16)=0.4022, p=$ 0.53; for the M. parviflora treatment $F(1,16)=29.79, p<0.001$; for the genotype and diet interaction $F(1,16)=0.04041, p=0.84$; for the M. parviflora treatment and diet interaction $F(1,16)=0.2594 p=0.62$; for the genotype and $M$. parviflora treatment interaction $F(1,16)=20.67 p<0.001$; for the genotype, $M$. parviflora treatment and diet interaction $F(1,16)=2.037, p=0.17$. b TNF (marker of M1 state) mRNA levels. Data are shown as mean $\pm S E M, n=3$ animals per group. Statistical analysis was performed by three-way ANOVA followed by Tukey's multiple comparisons test. This analysis revealed a significant effect for the genotype $F(1,16)=25.65 p<0.001$; for the diet $F(1,16)=5.758, p=0.03$; for the M. parviflora treatment $F(1,16)=32.4, p<0.001$; for the genotype and diet interaction $F(1,16)=4.955, p=0.04$; for the $M$. parviflora treatment and diet interaction $F(1,16)=$ $2.259 p=0.15$; for the genotype and M. parviflora treatment interaction $F(1,16)=26.77 p<0.001$; for the genotype, M. parviflora treatment and diet interaction $F(1,16)=2.189, p=0.16$. c Mgl1 (marker of M2 state) mRNA levels. Data are shown as mean $\pm S E M, n=3$ animals per group. Statistical analysis was performed by three-way ANOVA followed by Tukey's multiple comparisons test, and $\mathbf{d}$ TREM-2 mRNA levels. Data are shown as mean $\pm \mathrm{SEM}, \mathrm{n}=3$ animals per group. Statistical analysis was performed by three-way ANOVA followed by Tukey's multiple comparisons test. Microglia from 8-month-old Wt or 5XFAD mice were unstimulated or stimulated with LPS $(100 \mathrm{ng} / \mathrm{mL})$ in the presence or absence of MpHE $(M$. parviflora; $1 \mathrm{mg} / \mathrm{mL}$ ) for $24 \mathrm{~h}$. Control cells were treated with PBS (Ctrl) or MpHE alone (M. parviflora). Supernatants were used to determine TNF and IL6 levels by ELISA as described in the "Methods" section. e TNF levels. Data are shown as mean \pm SEM, $n=3$ animals per group. Statistical analysis was performed by three-way ANOVA followed by Tukey's multiple comparisons test. This analysis revealed a significant effect for the genotype $F(1,16)=7.878, p=0.0127$; for the LPS treatment $F(1,16)=17.74, p=0.0007$; for the $M$. parviflora treatment $F(1,16)=66.30, p<0.0001$; for the genotype and LPS treatment interaction $F(1,16)=6.105, p=0.0251$. $\mathbf{f} \| \mathrm{L} 6$ levels. Data are shown as mean $\pm S E M, n=3$ animals per group. Statistical analysis was performed by three-way ANOVA followed by Tukey's multiple comparisons test. This analysis revealed a significant effect for the genotype $F(1,16)=25.76, p=0.0001$; for the LPS treatment $F(1,16)=19.86, p=0.0004$; for the $M$. parviflora treatment $F(1,16)=309.3, p<$ 0.0001 ; for the genotype and LPS treatment interaction $F(1,16)=20.71, p=0.0003$ 

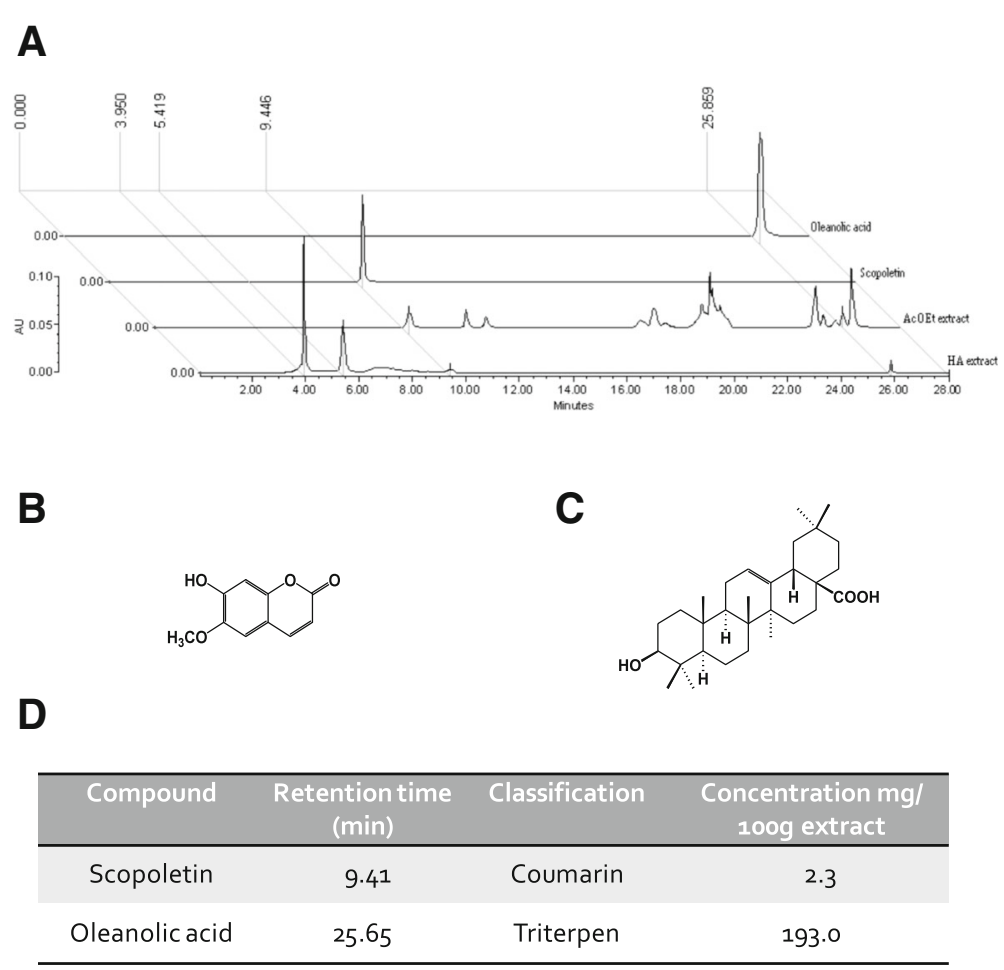

Fig. 9 The Malva parviflora hydroalcoholic extract contains scopoletin and oleanolic acid. a HPLC chromatograms comparing the hydroalcoholic (HA) and ethyl acetate (AcOEt) fractions from MpHE with reference standards of scopoletin and oleanolic acid. All samples were monitored at $345 \mathrm{~nm}$. b Chemical structure of scopoletin. c Chemical structure of oleanolic acid. $\mathbf{d}$ Principal compounds present in the hydroalcoholic extract of M. parviflora

content per gram of AcOet fraction and $101.9 \mathrm{mg}$ of oleanolic acid content per gram of AcOet fraction. Considering the yield of the HE ( $1 \mathrm{~g}$ of HE produces $0.019 \mathrm{~g}$ of AcOet fraction), the scopoletin concentration corresponds to $23 \mu \mathrm{g} / \mathrm{g}$ of $\mathrm{HE}$ and $1.93 \mathrm{mg} / \mathrm{g}$ of $\mathrm{HE}$ for the oleanolic acid (Fig. 9d). According to previous data indicating that oleanolic acid and scopoletin have anti-inflammatory activity [41, 42], both compounds inhibited LPS-induced NF- $\mathrm{kB}$ activity in mouse RAW-Blue macrophages (Additional file 3: Figure S3).

These data indicate that the anti-neuroinflammatory effect of the MpHE, observed in this study, might result from the presence of oleanolic acid and scopoletin.

\section{M. parviflora hydroalcoholic extract regulates the phagocytic capacity of microglial cells via the PPARY- CD36 pathway}

As shown, chemical characterization of MpHE determined the presence of oleanolic acid and scopoletin. Oleanolic acid is a natural agonist of the nuclear receptor peroxisome proliferator-activated receptor gamma (PPAR- $\gamma$ ) [43, 44]. Interestingly, PPAR- $\gamma$, through the induction of CD36 expression, mediates microglial amyloid $\beta$ plaques phagocytosis in the APP/PS1 mice [16]. Since MpHE stimulates the microglia phagocytosis activity from 5XFAD mice, we tested whether the improved microglial phagocytic activity resulting from MpHE involved PPAR- $\gamma$ activation. In accordance with this idea, MpHE increased the levels of PPAR- $\gamma$ in a concentration-dependent manner (Ctrl $v s M$. parviflora $0.1 \mathrm{mg} / \mathrm{mL} ; p=0.009$; Ctrl vs M. parviflora 1 $\mathrm{mg} / \mathrm{mL}, p=0.004$ ) (Fig. 10a) and to a similar extent than the PPAR- $\gamma$ agonist pioglitazone $(p=0.001)$ (Fig. 10a). In accordance with the fact that PPAR- $\gamma$ induces its own expression through a positive feedback loop [45], the PPAR$\gamma$-specific inhibitor GW9662 $(100 \mu \mathrm{M})$ prevented the increase in PPAR- $\gamma$ levels resulting from the MpHE treatment (M. parviflora $0.1 \mathrm{mg} / \mathrm{mL}$ vs $\mathrm{GW} 9662+M$. parviflora $0.1 \mathrm{mg} / \mathrm{mL}(p=0.04) ;$ M. parviflora $1 \mathrm{mg} / \mathrm{mL}$ vs GW9662 + M. parviflora $1 \mathrm{mg} / \mathrm{mL}(p=0.003)$, as well as that induced by pioglitazone $(p<0.001)$ (Fig. 10a). GW9662 acts as a potent antagonist of PPAR- $\gamma$ by covalently modifying a cysteine residue in the ligand binding site of PPAR- $\gamma$ [46]. These results show that MpHE regulates PPAR- $\gamma$ activity.

Since CD36 is a scavenger receptor involved in $A \beta$ phagocytosis [16], whose expression is controlled by PPAR- $\gamma$ [47], we tested the idea that the MpHE via PPAR- $\gamma$ regulates CD36 expression. Microglia primary cultures were left untreated or pre-treated with GW9662 for $1 \mathrm{~h}$, then incubated with MpHE $(1 \mathrm{mg} / \mathrm{mL})$ for $24 \mathrm{~h}$ 
A

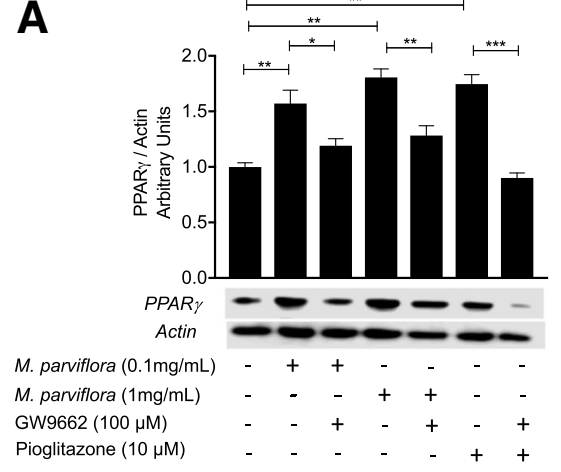

B
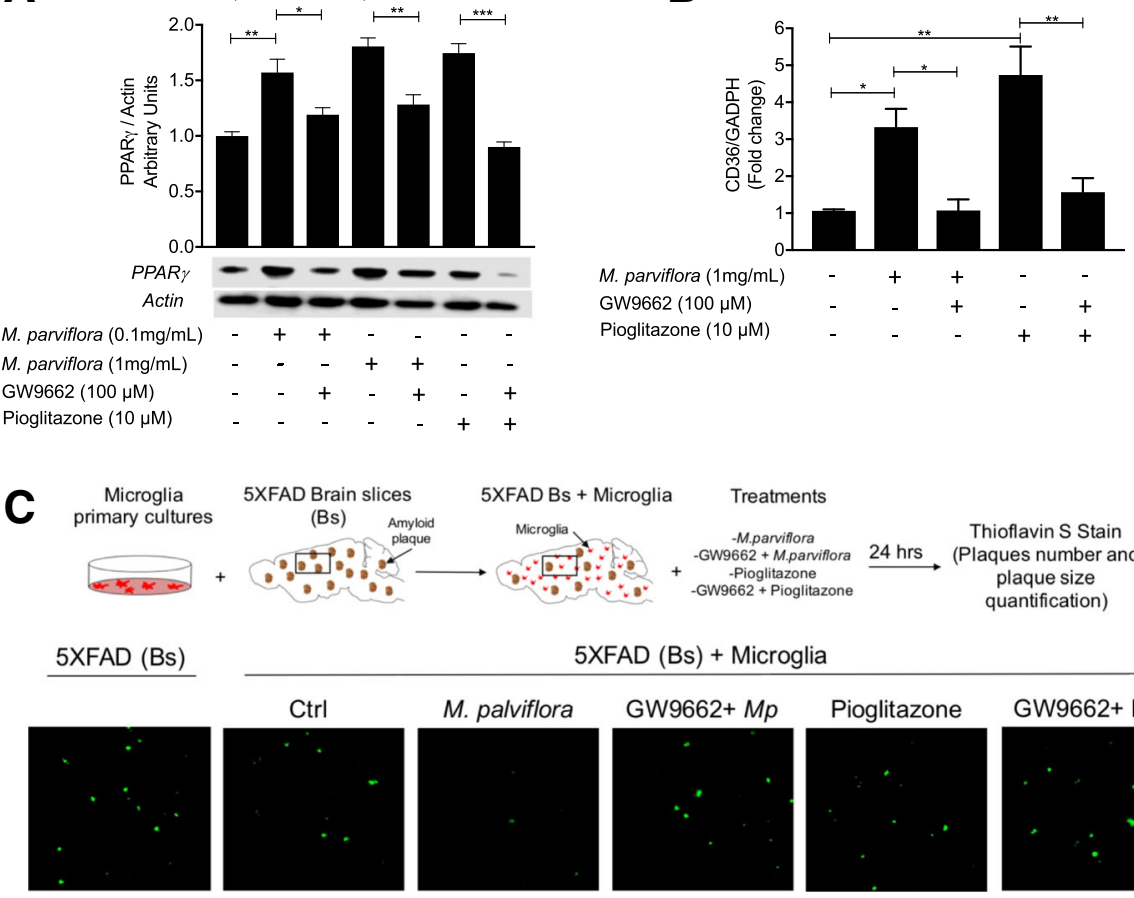

5XFAD Bs + Microglia

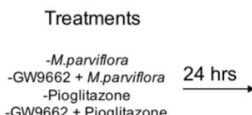

Thioflavin S Stain (Plaques number and plaque size quantification)

D

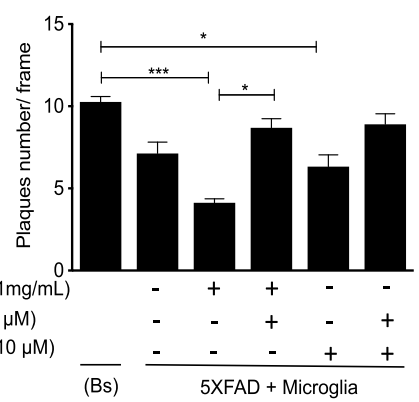

5XFAD (Bs) + Microglia

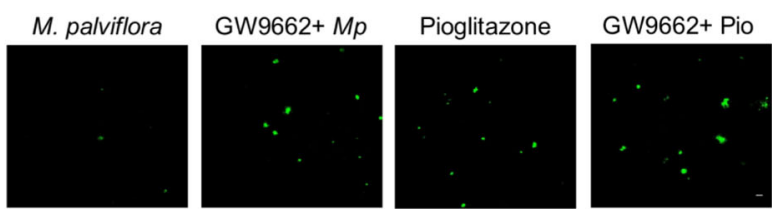

$\mathbf{E}$

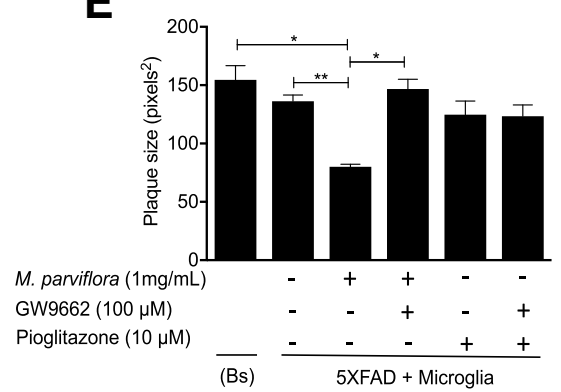

Fig. 10 Malva parviflora hydroalcoholic extract regulates the phagocytic capacity of microglial cells via PPARY-CD36 mediated mechanism. Microglial primary cultures were left untreated or pre-treated with GW9662, a specific PPAR- $\gamma$ inhibitor for $1 \mathrm{~h}$, following by incubation with MpHE or the PPAR- $\gamma$ agonist, pioglitazone, at the indicated concentration for $24 \mathrm{~h}$. a The PPAR- levels from the cell extracts of microglial primary cultures were determined by immunoblot using specific antibodies and the actin levels were used as internal control. Normalized densitometry values of PPAR- - (PPAR- $\gamma /$ actin) present in the extracts of microglial primary cultures in the presence of MpHE (Mp) or pioglitazone and GW9662. Data are shown as mean \pm SEM and were analyzed by one-way ANOVA. Ctrl vs Mp $0.1 \mathrm{mg} / \mathrm{mL}\left({ }^{* *} p=0.009\right) ; C \operatorname{trl}$ vs Mp $1 \mathrm{mg} / \mathrm{mL}\left({ }^{* *} p=0.004\right) ; C \operatorname{trl}$ vs pioglitazone (** $\left.{ }^{*} p=0.001\right) ; \mathrm{Mp} 0.1 \mathrm{mg} / \mathrm{mL}$ vs GW9662 +Mp $0.1 \mathrm{mg} / \mathrm{mL}\left({ }^{*} p=0.04\right) ; \mathrm{Mp} 1 \mathrm{mg} / \mathrm{mL}$ vs GW9662 + Mp $1 \mathrm{mg} / \mathrm{mL}\left({ }^{* *} p=0.003\right)$; Pioglitazone vs GW9662 + Pioglitazone (*** $<0.001$ ). b CD36 mRNA levels were determined by qPCR using total RNA from the microglial primary cultures treated as described above. Data were analyzed by one-way ANOVA. Ctrl vs Mp $\left({ }^{*} p=0.04\right) ;$ Ctrl vs pioglitazone $(* * p=0.002) ;$ Mp vs GW9662 + Mp (* $\left.{ }^{*} p=0.04\right)$; pioglitazone vs GW9662 + pioglitazone $\left({ }^{* *} p=0.005\right)$. c Representative micrographs from cortex of adult 5 XFAD mice alone (Bs) or in the presence of microglial primary cultures (5XFAD Bs + microglia) untreated (-) or pre-treated with M. parviflora or pioglitazone and GW9662. The slices were stained with thioflavin $\mathbf{S}$ and analyzed by confocal microscopy. $\mathbf{d}$ The plaques number were quantified. Data were analyzed by one-way ANOVA. Bs vs M. parviflora (*** $p<0.001)$; Bs vs pioglitazone ( $\left.{ }^{*} p=0.03\right)$; M. parviflora vs GW9662 + M. parviflora $\left({ }^{*} p=0.04\right)$. e The plaques size was quantified. Data were analyzed by one-way ANOVA. Bs vs M. parviflora $\left({ }^{*} p=0.03\right) ;$ Ctrl vs M. parviflora $\left({ }^{* *} p=0.007\right) ; M$. parviflora vs GW9662 + M. parviflora ( $\left.{ }^{*} p=0.02\right)$

and CD36 mRNA levels were measured. CD36 mRNA levels were upregulated in response to $\operatorname{MpHE}(p=0.04)$ but prevented by GW9662 $(p=0.04)$ (Fig. 10b). The CD36 expression levels induced by the MpHE were similar to those resulting from exposing microglial cell to pioglitazone ( $p=0.002)$ (Fig. 10b).
Next, we evaluated whether PPR- $\gamma$ activity was required for the enhanced microglia phagocytic activity mediated by the MpHE. The increase in CD36 expression correlated with the increased phagocytic activity of microglial cells exposed to the $\mathrm{MpHE}$ towards amyloid $\beta$ plaques. Brain slices from 5XFAD transgenic mice exposed to microglia 
that was previously treated with the $\mathrm{MpHE}$ showed a significant reduction in both the number $(p<0.001)$ (Fig. $10 \mathrm{c}, \mathrm{d})$ and size $(p=0.03)$ (Fig. 10c, e) of amyloid $\beta$ plaques that remained at the end of the experiment compared with those found in the slides exposed to nontreated microglia (Fig. 10c-e). Again, this effect was prevented by the PPAR- $\gamma$ inhibitor GW9662 (Fig. 10c-e). Activating microglia with the PPAR- $\gamma$ agonist also resulted in a significant reduction in the number of amyloid $\beta$ plaques $(p=0.03)$, an effect that was prevented by the PPAR- $\gamma$ inhibitor (Fig. 10d). Interestingly, pioglitazone had no effect on the size of the amyloid $\beta$ plaques remaining on the tissue slide (Fig. 10e). To further corroborate these data, 5XFAD transgenic mice were treated with MpHE in the absence or presence of GW9662 and the amyloid $\beta$ plaques phagocytized by microglia was evaluated by flow cytometry using methoxy-X04 (Fig. 11a). MpHE in vivo administration increased the $\mathrm{CD} 11 \mathrm{~b}+/ \mathrm{CD} 36+$ population (Fig. 11b, left and middle panel) as well as the CD36 expression levels (Fig. 11b right panel) via a PPAR- $\gamma-$ dependent mechanism since GW9662 prevented this induction (Fig. 11b middle and right panels). The increase in CD36 expression correlated with increased phagocytic activity of microglial cells towards amyloid $\beta$ plaques in the MpHE-treated 5XFAD since we observed an increase in both the $\mathrm{CD}^{2} 6^{+} /$methoxy-X04 ${ }^{+}$cells (Fig. 11c middle panel) and in the methoxy-X04 staining (Fig. 11c right panel). Importantly, the increased microglia phagocytic activity was prevented by the PPAR- $\gamma$ inhibitor GW9662 (Fig. 11c, middle and right panels). These results show that MpHE enhances microglia phagocytic activity towards amyloid $\beta$ plaques by promoting CD36 expression via PPAR- $\gamma$ activity in the 5XFAD transgenic mice. Accordingly, MpHE in vivo administration increased PPAR- $\gamma$ levels in the 5XFAD mice frontal cortex (Wt HFD vehicle $v s$ Wt HFD Mp, $p=0.0050$; 5 XFAD ND vehicle $v s$ XFAD ND Mp, $p=0.0934 ; 5$ XFAD HFD vehicle $v s$ XXFAD HFD Mp, $p=0.0036$ ) (Fig. 12a).

As described above, $\mathrm{MpHE}$ contains oleanolic acid, a natural agonist of PPAR- $\gamma(43,44)$. Therefore, we tested whether the improved microglial phagocytic activity resulting from $\mathrm{MpHE}$ treatment involved oleanolic acidmediated PPAR- $\gamma$ activation. In accordance with this idea, oleanolic acid increased PPAR- $\gamma$ levels specifically in microglia (Ctrl vs $4.5 \mu \mathrm{g}$ oleanolic acid, $p=0.0414$; Ctrl vs $45 \mu \mathrm{g}$ oleanolic acid, $p=0.0608$ ). Congruently with the fact that PPAR- $\gamma$ induces its own expression through a positive feedback loop [45], the PPAR- $\gamma$ specific inhibitor GW9662 $(100 \mu \mathrm{M})$ prevented the increase in PPAR- $\gamma$ levels resulting from the oleanolic acid treatment $(4.5 \mu \mathrm{g} / \mathrm{mL}$ oleanolic acid $v s$ GW9662 $+4.5 \mu \mathrm{g} / \mathrm{mL}$ oleanolic acid $(p=0.0116) ; 45 \mu \mathrm{g} / \mathrm{mL}$ oleanolic acid $\nu s$ GW9662 $+45 \mu \mathrm{g} / \mathrm{mL}$ oleanolic acid $(p=0.0079)$ ) (Fig. 12b). Together, these results indicate that the MpHE promotes microglia phagocytosis and degradation of amyloid $\beta$ plaques by inducing PPAR- $\gamma$ mediated CD36 expression (Fig. 12c).

\section{Discussion}

Plant extracts have been used as an alternative therapy to revert the $\mathrm{AD}$ marks. It is thought that the mixture of compounds with synergistic activities as anti-oxidant and anti-inflammatory activities favors $A \beta$ reduction, acetylcholinesterase inhibition, and monoamines modification $[48,49]$. Previously, the M. parviflora extract has been shown to present hypoglycemic, anti-oxidant, and anti-inflammatory activities $[20,21,50]$ and even it has been reported to have a beneficial effect against $A \beta$ injected mice [51]. In the present study, we demonstrate the neuroprotective effect of a long-term treatment with $\mathrm{MpHE}$ in the 5XFAD mouse model of AD. This model has been widely used to examine the therapeutic value of candidate agents for $\mathrm{AD}$ treatment [52-54], displaying age-dependent neurological and motor deficits that mimic common phenotypes seen in AD patients, without the presence of neurofibrillary tangles [55]. In addition, we also provide evidence indicating that the $\mathrm{MpHE}$ attenuates the negative effect of chronic peripheral inflammation on the development of $\mathrm{AD}$ pathological hallmarks. The MpHE reduced adipose tissue inflammation and insulin resistance in obese mice fed with a HFD; a well-established experimental approach to induce insulin resistance [56]. Together, our results show for the first time that a long-term treatment with a $\mathrm{MpHE}$ attenuates both peripheral and central inflammation resulting in improved memory and learning abilities in a familial Alzheimer's disease model. The molecular mechanism activated by the MpHE involves the activation of the PPAR- $\gamma$ pathway and increased scavenger receptor CD36 expression which improves microglia phagocytic activity thus reducing $A \beta$ load and inflammation in the CNS. Therefore, our data uncover the signaling pathway regulated by the MpHE resulting in neuroprotection.

Our phytochemical analysis identified two compounds in the MpHE, oleanolic acid and scopoletin. Interestingly, both compounds have hypoglycemic, antiinflammatory, and anti-oxidant properties. A proposed anti-inflammatory mechanism for oleanolic acid involves the upregulation of the transcription factor $\mathrm{Nrf} 2$, which inhibits the expression of NF-kB [42]. As oleanolic acid, the scopoletin anti-inflammatory effect also involves the inhibition of the NF-kB and p38 MAPK pathways [57]. Congruent with oleanolic acid and scopoletin anti-NF$\kappa B$ activity, here, we demonstrate that the MpHE decreases the NF- $\mathrm{kB}$ activation in a concentrationdependent manner. Furthermore, our ex vivo experiments show that this treatment effectively prevents 


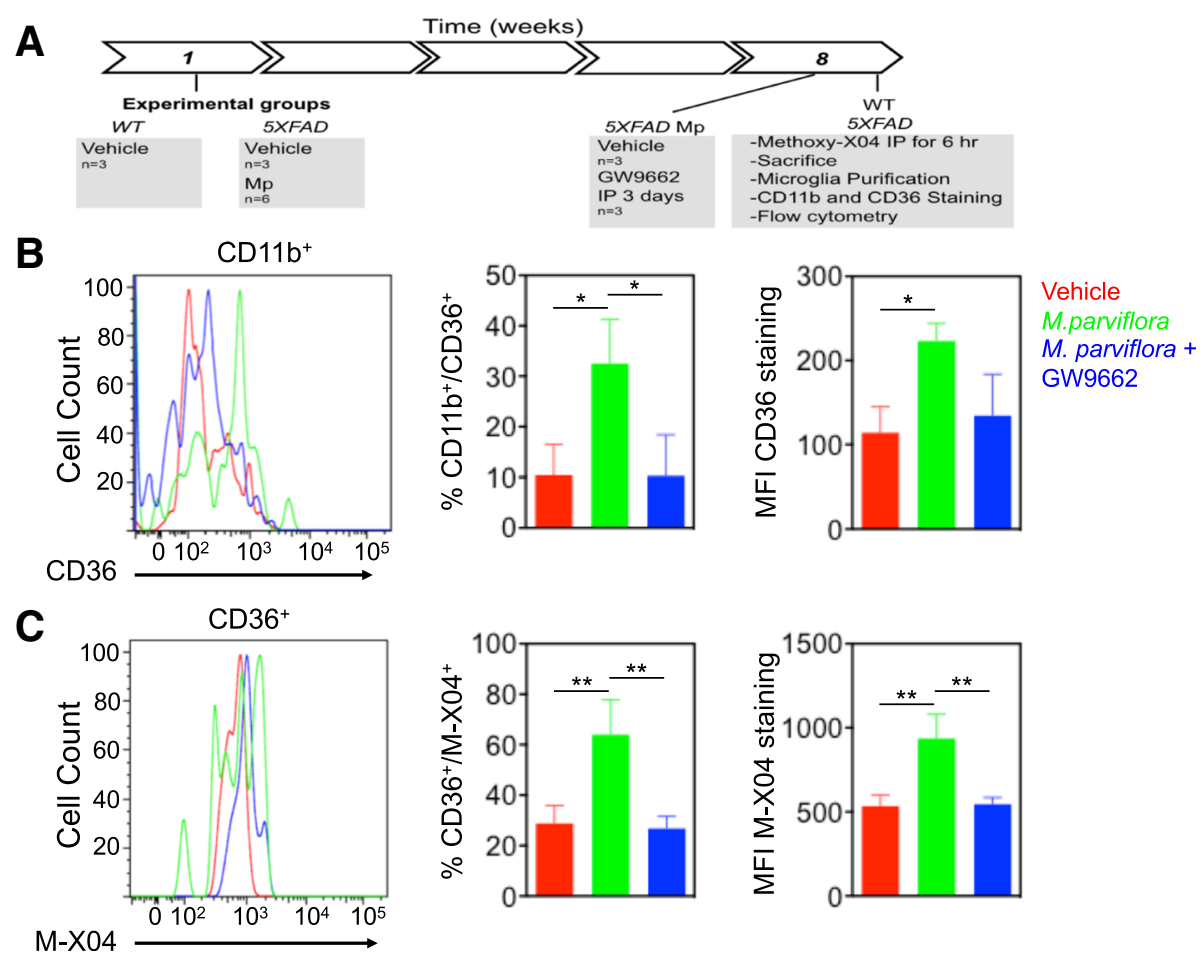

Fig. 11 Malva parviflora hydroalcoholic extract regulates the phagocytic capacity of microglial cells via PPARy-CD36 mediated mechanism in the 5XFAD transgenic mice. a Graphical time line of the study design and experimental procedures. The 5XFAD transgenic mice received $50 \mathrm{mg} / \mathrm{kg} /$ day of the MpHE (Mp) or water (Vehicle) intragastrically during 2 months. After, the mice were intraperitoneally (IP) injected with GW9662 (5 mg/ $\mathrm{kg}$ ), a specific PPAR- $\gamma$ inhibitor, or vehicle (5\% DMSO/95\%PBS) for the last 3 days before sacrifice. For the in vivo amyloid $\beta$ phagocytosis assay, mice were intraperitoneally injected $6 \mathrm{~h}$ before sacrifice with methoxy-X04 $(10 \mathrm{mg} / \mathrm{kg})$. The presence of A $\beta$ peptides in the microglial cells were analyzed by flow cytometry. $\mathbf{b}$ CD36 expression in microglia $\left(\mathrm{CD} 11 \mathrm{~b}^{+}\right.$) from 5XFAD transgenic mice untreated (Vehicle) or treated with MpHE alone (M. parviflora) or with MpHE and GW9662 (M. parviflora+GW9662) determined by flow cytometry. Left panel: A representative histogram depicts CD36 expression in the CD11 b cells from 5XFAD transgenic brain. Middle panel: \% of the CD11 b $/$ CD36 ${ }^{+}$cells. Data (mean \pm SD) were analyzed by one-way ANOVA followed by Tukey's post hoc test. Percentage CD11b+/CD36+ 5XFAD vehicle vs 5XFAD Mp (*p $p=0.0298) ; 5 X F A D$ Mp vs 5XFAD Mp + GW9662 ( $\left.{ }^{*} p=0.0291\right)$. Right panel: CD36 expression levels. MFI CD 11 b ${ }^{+} / \mathrm{CD} 36^{+} 5$ XFAD Vehicle vs 5XFAD Mp $\left({ }^{*} p=0.0228\right) . \mathbf{c}$ Left panel: cytometry analysis of A $\beta$ peptides phagocytized by microglia (CD11b+/CD36+) from adult 5XFAD mice untreated (Vehicle) alone (M. parviflora) or with MpHE and GW9662 (M. parviflora+GW9662) that received methoxy-X04 (M-X04). Left panel: representative histogram is shown. Middle panel: percent of the $\mathrm{CD} 36^{+} / \mathrm{M}-\mathrm{X} 04^{+}$cells data (mean $\pm \mathrm{SD}$ ) were analyzed by one-way ANOVA followed by Tukey's post hoc test. Percentage $\mathrm{CD} 36^{+} /$Methoxy-X04 ${ }^{+}$5XFAD vehicle vs 5 XFAD Mp $\left(^{* *} p=0.0089\right) ; 5$ XFAD Mp vs 5XFAD Mp + GW9662 $(* * p=0.0069)$. Right panel: phagocyted M-XO4 levels. MFI CD36 ${ }^{+}$/Methoxy-X04 5XFAD Vehicle vs 5XFAD Mp (**p=0.0047); 5XFAD Mp vs. 5XFAD $\mathrm{Mp}+\mathrm{GW} 9662\left({ }^{* *} p=0.0054\right)$

microglia activation by inhibiting the morphological changes typically induced by LPS, thus confirming the anti-inflammatory effects of MpHE previously described using ear edema and vascular permeability models [21]. Additionally, it has been shown that synthetic triterpenoid analogs of oleanolic acid attenuate microglia activation and the pro-inflammatory phenotype [58].

In contrast with previous studies showing that a HFD had no effect on the $A \beta$ plaque burden in the hippocampus from old 3xTgAD mice [59], we found that HFD increases the deposition of hippocampal $\beta$-amyloid plaques in the 5XFAD mice model. This correlated with the fact that these animals were glucose intolerant and showed insulin resistance, which is in agreement with experimental evidence indicating that the energy metabolism in the brain plays a key role in $\mathrm{AD}$ development
[60-62]. This is consistent with previous reports that confirm impairment in hippocampal synaptic plasticity in animals fed with HFD [63-65].

Recent studies showed that a short-term HFD feeding (16 weeks) to 5XFAD mice does not induce metabolic disorder, including blood glucose levels, and does not increase body weight, although the HFD had a notorious impact on the cognition, thus considering these effects as independent phenomena [66]. However, insulin released by the pancreas crosses the blood-brain barrier and binds to and activates its specific receptor in the $\mathrm{CNS}$, including those expressed in the hippocampus. Accordingly, insulin enhances memory in healthy humans and rodents $[67,68]$. Thus, impaired insulin receptor signaling contributes to the development of hippocampal insulin resistance (IR). Clinical and preclinical studies 


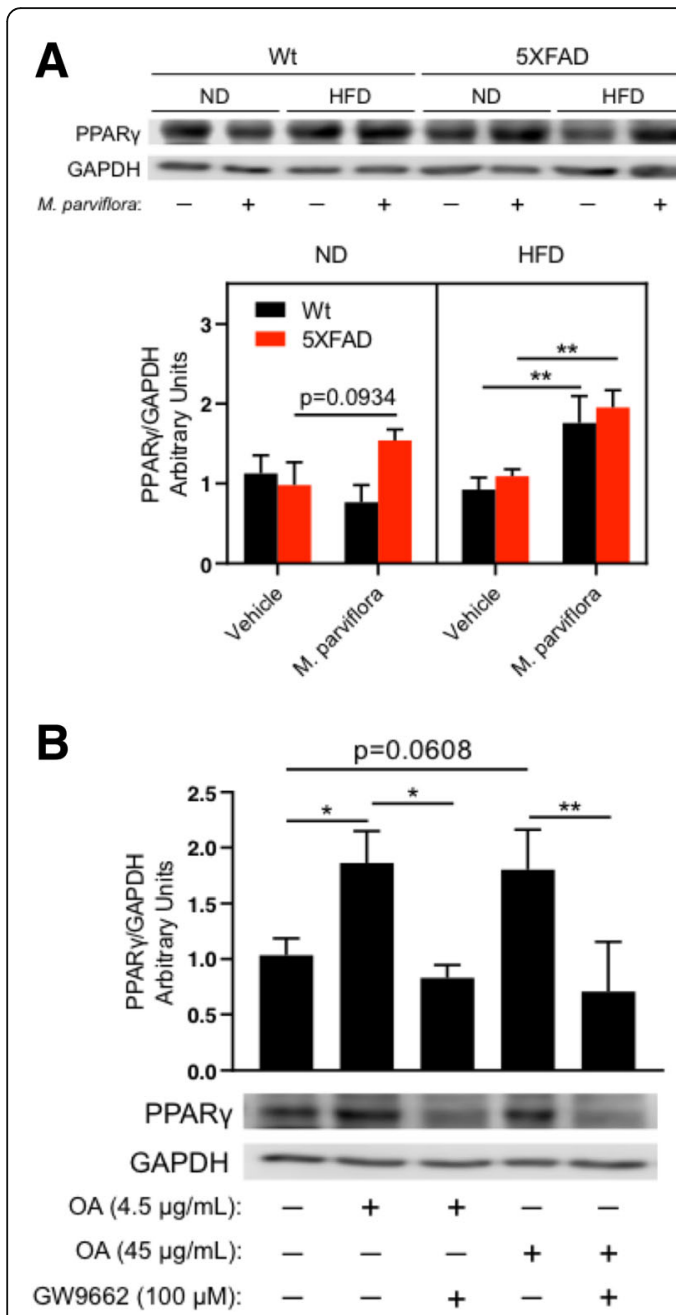

Fig. 12 Malva parviflora hydroalcoholic extract regulates PPARY levels in the 5XFAD transgenic mice. The 5XFAD and Wt mice were fed with either normal diet (ND) or high-fat diet (HFD) non-treated (Vehicle) or treated with M. parviflora hydroalcoholic extract (M. parviflora). The PPAR- $\gamma$ levels from the frontal cortex cell extracts were determined by immunoblot using specific antibodies and the GAPDH levels were used as internal control. a Normalized densitometry values of PPAR- $\gamma$ (PPAR- $y / G A P D H)$ present in the frontal cortex cell extracts of 5 XFAD and Wt mice. Data (mean \pm SD) were analyzed by three-way ANOVA followed by Tukey's multiple comparisons test. This analysis revealed a significant effect for the genotype $F(1,16)=7.529, p=0.0144$; for the diet $F(1,16)=13.37, p=0$-0021; for the $M$. parviflora treatment $F(1,16)=28.11, p<0.0001$; for the genotype and diet interaction $F(1,16)=0.5415, p=0.4725$; for the $M$. parviflora treatment and diet interaction $F(1,16)=17.37, p=0.0007$; for the genotype and $M$. parviflora treatment interaction $F(1,16)=6.946, p<0.0180$; for the genotype, $M$. parviflora treatment and diet interaction $F(1,16)=$ 6.111, $p=0.0250$. b Microglial primary cultures were left untreated or pre-treated with GW9662, a specific PPAR- $\gamma$ inhibitor for 1 h, following by incubation with oleanolic acid (OA), at the indicated concentration for $24 \mathrm{~h}$. The PPAR- $\gamma$ levels from the cell extracts of microglial primary cultures were determined by immunoblot using specific antibodies and the GAPDH levels were used as internal control. Normalized densitometry values of PPAR $-\gamma$ (PPAR- $\gamma /$ GAPDH) present in the extracts of microglial primary cultures in the presence of oleanolic acid. Data (mean \pm SD) were analyzed by one-way ANOVA followed by Tukey's post hoc test. Ctrl vs $4.5 \mu \mathrm{g} / \mathrm{mL}$ oleanolic acid ( $\left.{ }^{*} p=0.0414\right) ; 4.5 \mu \mathrm{g} / \mathrm{mL}$ oleanolic acid vs GW9662 + oleanolic acid $4.5 \mu \mathrm{g} / \mathrm{mL}\left({ }^{*} p=0.0116\right) ; 45 \mu \mathrm{g} / \mathrm{mL}$ oleanolic acid vs GW9662 $+45 \mu \mathrm{g} / \mathrm{mL}$ oleanolic acid $\left(^{* *} p=0.0079\right) ;$ c Model of the mechanism by which M. parviflora hydroalcoholic extract (HE) diminishes neuroinflammation. Chronic inflammation compromises microglia clearance functions by reducing the expression of the scavenger receptor CD36. The peroxisome proliferator-activated receptor (PPAR- $\gamma$ ) suppress inflammatory gene expression and promotes phagocytosis by regulating CD36 expression a scavenger receptor involved in microglia-dependent amyloid plaque destruction. According with this, our results indicate that a component present in the M. parviflora extract, probably oleanolic acid, based on previous studies [43] and our data, induces PPAR- $y$ activation that results in the upregulation of the scavenger receptor CD36 expression, thus leading to microglia-enhanced phagocytic, amyloid plaque clearance activity, diminished neuroinflammation, and improved learning and memory

suggest that hippocampal IR leads to the neuroplasticity deficits observed in both type II diabetes and AD. Recently, it has been proposed that neuroinflammation may serve as a link between aging, type II diabetes, and $\mathrm{AD}$ by causing IR $[14,69]$. Pro-inflammatory molecules (e.g., TNF, IL-6, IL-1 $\beta$ ) are increased in type II diabetes 
and $\mathrm{AD}$, which may compromise the hippocampal insulin receptor expression and/or signaling. For instance, TNF may cause hippocampal IR by increasing serine phosphorylation of IRS1 [70]. Although further studies are needed to establish whether IR in the CNS regulates memory by itself or in combination with peripheral IR, experimental data support that enhancement of hippocampal insulin receptor signaling could reduce or reverse the memory deficits observed in type II diabetes and $\mathrm{AD}$ [71]. These observations point out the importance of establishing pharmacological and/or preventive strategies to improve cognitive deficits in individuals suffering metabolic syndrome. Interestingly, here, we show that the MpHE abolished the increase in TNF levels in the cortex of lean and obese 5XFAD transgenic mice.

Our results show also that the long-term treatment with $\mathrm{MpHE}$ significantly reduces the body weight gain, the impairment in the glucose metabolism in transgenic and non-transgenic mice and surprisingly, reduced the $\mathrm{A} \beta$ deposition in transgenic mice. Furthermore, we observed that $\mathrm{MpHE}$ significantly decreases the escape latency in the learning and memory tests, in accordance with a previous study where an ethanolic M. parviflora extract increased the learning and memory along with reduced reactive oxygen species (ROS) levels after injection of $A \beta$ in mice [51]. These data are consistent with oleanoic acid and scopoletin neuroprotective effects. The oleanolic acid isolated from Aralia cordata confers neuroprotection in rat cortical neuronal cultures by inhibiting neuronal death and the generation of ROS induced by $\mathrm{A} \beta$. Equally, the ethanolic extract of Aralia cordata possesses antidementia activities in mice injected intracerebroventricularly with $A \beta$ peptides [72].

Additionally, scopoletin increases presynaptic activitydependent acetylcholine (ACh) release, enhances hippocampal long-term potentiation (LTP), and improves cognition in cholinergically impaired and in ageimpaired mice. Scopoletin neuroprotective effect might result from interacting with nicotinic $\mathrm{ACh}$ receptors (nAChRs) enhancing NMDA-dependent LTP [73]. Activated nAChRs can promote neuronal survival and may also decrease the synthesis and deposition of $A \beta$ peptides [74]. If the neuroprotective effects of Malva parviflora involves the interaction of the scopoletin present in the extract with the nAChRs is yet to be determined.

During the development and in adulthood, the microglial cells maintain the brain homeostasis perceiving their microenvironment. The healthy state of the microglial cells is altered by the presence of soluble and aggregated $A \beta$, by the synaptic degeneration observed in the early $\mathrm{AD}$, among other signals. This causes an increase in the production of inflammatory molecules from the microglia leading to reprograming the expression of receptors involved in the AD progression $[32,75]$, for example, TNF decreased the expression of scavenger receptor A (SRA) and $\mathrm{CD} 36$ resulting in reduced $\mathrm{A} \beta$ uptake [33]. Here, we identified the neuroprotector effect of MpHE against the $\mathrm{AD}$ progression by the ability to regulate the microglia activation and its phagocytic capacity, increasing the accumulation of ramified microglia with long and thin processes around the $A \beta$ plaques in the cortex and hippocampus. Previous work has demonstrated that microglial primary cultures from adult mice are not compromised in their ability to recognize $A \beta$ fibrils but have deficient phagocytic capacity when compared to that of early postnatal microglial cultures [76]. Interestingly, the MpHE increases the phagocytic index in primary microglial cultures from early postnatal and even from 8- and 10months-old 5XFAD mice. This effect correlated with a reduction in the M1 pro-inflammatory phenotype since treatment with $\mathrm{MpHE}$ clearly promoted a reduction in CD86 and TNF expression levels in both lean or obese 5XFAD mice. Thus, MpHE may alleviate the negative effect of the inflammatory pathways on the insulin receptor signaling and in this way, reverse the memory deficits observed in type II diabetes and AD.

TREM-2 is a molecule directly related to the phagocytic capacity of microglial cells [77] and to the reduction of the neuronal damage produced by $A \beta$ plaques [78]. According with the fact that TREM-2 expression is upregulated in different mice models of $\mathrm{AD}$ in a timedependent manner [79], here, we observed that M. parviflora treatment tended to maintain high levels of TREM-2 expression in the cortex of 5XFAD mice at 9 months of age. Recently, it has been described a novel microglia subpopulation associated with neurodegenerative diseases (DAM) that is beneficial for $\mathrm{AD}$ [80]. The DAM program is activated in two-step checkpoints where microglia switch from homeostatic to stage 1 DAM (TREM2 independent) and to stage 2 DAM (TREM2 dependent) at late stages of the AD (8 months). Interestingly, the TREM2-dependent stage is associated with phagocytic activity which correlates with previous observations showing that absence of TREM2 in microglia at the late stage of $\mathrm{AD}$, but not at the early stages, exacerbates the disease [81]. Whether M. parviflora accelerates the DAM phenotype (TREM2 dependent) to increase the ability of microglia to digest amyloid plaques that results in neuroprotection warrants additional investigation. Also, our results point out at CD36 as the scavenger receptor mediating microglia phagocytosis of amyloid $\beta$ plaques in response to MpHE. This involves PPAR $\gamma$ activation, probably mediated by oleanolic acid $[43,44]$ present in the M. parviflora HE and the subsequent induction of CD36 expression. In agreement with previous results [45], microglia exposure to pioglitazone resulted in increased PPAR $\gamma$ protein levels. Interestingly, $M$. parviflora HE had the same effect, suggesting that 
pioglitazone and the $M$. parviflora HE activate PPAR $\gamma$ by a similar mechanism. Although PPAR $\gamma$ activation, resulting from pioglitazone exposure, promoted CD36 expression to a similar extent as that resulting from the $\mathrm{MpHE}$ treatment, the phagocytosis and clearance activity of pioglitazone-treated microglia towards amyloid $\beta$ plaques was reduced when compared with that of microglia treated with the MpHE. This suggests that the MpHE through its anti-inflammatory effects might also activate autophagy, a mechanism that is also critical for amyloid $\beta$ plaques clearance and impaired by the inflammatory environment elicited by amyloid $\beta$ peptides [8].

Individuals with type II diabetes have increased risk for developing $\mathrm{AD}$ by at least twofold [82]. However, the precise mechanism for this association is not known. Here, we showed that alterations in glucose metabolism (i.e., IR) resulting from obesity exacerbate the memory loss induced by $\mathrm{A} \beta$ accumulation. Treatment with the MpHE restores insulin sensitivity and glucose tolerance in obese mice, which correlated with a diminished inflammatory environment and increased cognition in the 5XFAD mice. Additionally, we found that MpHE regulates PPAR- $\gamma$ activity and mediates microglial amyloid $\beta$ plaques phagocytosis. Thus, by regulating the microglia phagocytic activity via a PPAR- $\gamma$-dependent mechanism and preventing the proinflammatory M1 phenotype, $M$. parviflora reduces $\beta$ amyloid plaque load and improves learning and memory in lean and obese mice. Additionally, we do not discard the possibility that MpHE through the activation of PPAR $\gamma$, prevents IKK activity [44] and therefore IRS phosphorylation on serine residues, thus improving insulin signaling directly on hippocampal neurons reversing the memory deficits observed in type II diabetes and AD. Therefore, $M$. parviflora-derivative compounds represent an alternative to prevent cognitive impairment associated with a metabolic disorder as well as an effective prophylactic candidate for $\mathrm{AD}$ progression.

\section{Conclusions}

Peripheral inflammation resulting from obesity has been shown to exacerbate learning and memory loss in humans and in animal models of AD. Here, we show that obesity further promoted $A \beta$ plaque formation in the 5XFAD mice. However, administration of the MpHE reversed obesity-mediated deleterious effects of $A \beta$ deposition on memory and learning. The MpHE attenuated proinflammatory M1 microglia activation while sustaining anti-inflammatory M2 microglia, since CD86 and TNF expression levels observed in the cortex of 5XFAD mice fed with ND and HFD were reduced in the cortex from 5XFAD mice treated with MpHE. In parallel, MpHE tended to increase the levels of Mgl1 and from TREM2 in the cortex of lean and obese 5XFAD mice. In accordance with this, MpHE reduced the astrogliosis throughout the hippocampus of HFD-fed 5XFAD mice. In addition, $\mathrm{MpHE}$ increases microglia phagocytic activity via a PPAR$\gamma /$ CD36-dependent mechanism. Our data indicate that by regulating microglia phagocytic activity and by preventing the microglia pro-inflammatory M1 phenotype, $M$. parviflora reduces $\beta$-amyloid plaque load and improves learning and memory in lean and obese mice. Our studies also demonstrate that MpHE can prevent not only HFDinduced neuroinflammation, but also systemic inflammation since it reduces the infiltration of immune cells to the adipose tissue and delays the increase in body weight and prevents the systemic insulin resistance and glucose intolerance produced by HFD in the 5XFAD mice. Thus, by regulating the microglia phagocytic activity via a PPAR- $\gamma /$ CD36-dependent mechanism and preventing the pro-inflammatory M1 phenotype, MpHE reduces the levels of pro-inflammatory molecules (e.g., TNF, IL-6), thus improving learning and memory in obese mice, which could result from restored insulin receptor signaling in hippocampal neurons. Strategies to prevent obesityassociated brain dysfunction are limited. M. parvifloraderivative compounds offer a novel adjunct therapeutic approach to ameliorate obesity-associated peripheral inflammation and neuroinflammation. Therefore, $M$. parviflora may be a safe and effective alternative to the conventional NSAIDs used for the treatment of neurodegenerative diseases as $\mathrm{AD}$.

\section{Additional files}

Additional file 1: Figure S1. Malva parviflora hydroalcoholic extract at three different doses protects from learning and memory deficit in LPS injected mice. (PDF $184 \mathrm{~kb}$ )

Additional file 2: Figure S2. Malva parviflora extract reduces adipose tissue inflammation in 5XFAD transgenic mice fed with high fat diet. (PDF $135 \mathrm{mb}$ )

Additional file 3: Figure S3. Oleanolic acid and scopoletin inhibit LPSinduced NF-kB activity in mouse RAW-Blue macrophages. (PDF 283 kb)

\section{Abbreviations}

ACh: Acetylcholine; AD: Alzheimer's disease; APP: Amyloid precursor protein; AUC: Area under the curve; AB: Amyloid B; DMEM: Dulbecco's Modified Eagle Medium; GFAP: Glial fibrillary acidic protein; GTT: Glucose tolerance test; HFD: High-fat diet; IL-1ß: Interleukin 1 beta; IL-6: Interleukin 6; IR: Insulin resistance; IRT: Insulin resistance test; LPS: Lipopolysaccharide; LTP: Long-term potentiation; M. parviflora: Malva parviflora; MpHE: M. parviflora leaf hydroalcoholic extract; nAChRs: Nicotinic ACh receptors; ND: Normal diet; NSAIDs: Non-steroidal anti-inflammatory; PBS: Phosphate buffer saline; PFA: Paraformaldehyde; PPAR- $\gamma$ : Peroxisome proliferator-activated receptor gamma; ROS: Reactive oxygen species; RT: Room temperature; SEAP: Embryonic alkaline phosphatase; SRA: Scavenger receptor A; TNF: Tumor necrosis factor

\section{Acknowledgements}

We thank Oswaldo López-Gutiérrez for technical support and E. Melchy for the flow cytometry analyses. The authors are also grateful to the M. Sci. Andrés Saraleguí Amaro, to Dr. Jaime Arturo Pimentel Cabrera, and to Q.F.B. Xochitl Alvarado Affantranger, at the Laboratorio Nacional de Microscopía Avanzada (UNAM), for imagen acquisition presented in this study; to S.D. Rodríguez at the Unidad de Histología (Instituto de Fisiología Celular-UNAM) 
for tissue histological processing; to P. Gaytan for kindly donating the fluorescent E. coli used in this study; and also to G. Cabeza, R. Blancas, and E. Mata for animal care.

This work was performed in fulfillment of the requirements for a $\mathrm{PhD}$ degree of Elisa Medrano Jimenez who is enrolled in the Programa de Doctorado en Ciencias Biomédicas (PDCB) at the Universidad Nacional Autónoma de México. The student received fellowship (576297) from CONACYT.

\section{Authors' contributions}

EM-J designed and performed experiments, analyzed and interpreted the data, and wrote the manuscript. IJ-FC conceived the study, performed experiments, and analyzed and interpreted the data. MP-E designed and performed experiments, analyzed and interpreted the data, carried out the statistical analyses, and wrote the manuscript. CER-S performed the in vivo dose-response experiments, analyzed and interpreted the data, and helped to draft the final version of the paper. LA-A and JC-M carried out experiments. AZ performed experiments, analyzed data, and provided infrastructure to carry out some experiments. MH-R, EJ-F, and JT analyzed data and provided infrastructure to carry out some experiments. GP-A designed, analyzed, and interpreted the data and wrote the manuscript. LP-M conceived, coordinated, and supervised the study; designed, analyzed, and interpreted the data; and wrote the manuscript. All authors read and approved the final version of this manuscript.

\section{Funding}

This work was supported by the CONACyT (grant numbers 155290 and IFC 2016-2282 to L.P.-M. and 154542 to G.P.-A.) and by the DGAPA-PAPIIT (grant numbers IN209212 and IN213316 to L.P.-M., IN227510 and IN212316 to G.P.A., IA203416 and IA203318 to M.P.E). We also thank the IMSS support (FIS/ IMSS/PROT/G11-2/1018).

\section{Availability of data and materials}

The data supporting the findings of this study are presented within the manuscript.

\section{Ethics approval}

The Institutional Bioethical Committee approved all animal experiments described in this study.

\section{Consent for publication}

Not applicable

\section{Competing interests}

The authors declare that they have no competing interests.

\section{Author details \\ 'Laboratorio de Neuroinmunobiología, Departamento de Medicina Molecular y Bioprocesos, Instituto de Biotecnología, Universidad Nacional Autónoma de México (UNAM), A.P. 510-3, CP, 62210 Cuernavaca, Morelos, México. ${ }^{2}$ Centro de Investigación Biomédica del Sur, Instituto Mexicano del Seguro Social (IMSS), Argentina No. 1, CP 62790 Xochitepec, Morelos, México. ${ }^{3}$ Present address: CONACYT-Hospital Infantil de México Federico Gómez, CP 06720 Ciudad de México, México.}

\section{Received: 21 September 2018 Accepted: 10 June 2019}

\section{Published online: 10 July 2019}

\section{References}

1. Wortmann M. Dementia: a global health priority - highlights from an ADI and World Health Organization report. Alzheimers Res Ther. 2012;4(5):40.

2. Reitz C, Mayeux R. Alzheimer disease: epidemiology, diagnostic criteria, risk factors and biomarkers. Biochemical Pharmacol. 2014;88(4):640-51.

3. Latta $\mathrm{CH}$, Brothers HM, Wilcock DM. Neuroinflammation in Alzheimer's disease; a source of heterogeneity and target for personalized therapy. Neuroscience. 2015;302:103-11.

4. Haass C. Take five--BACE and the gamma-secretase quartet conduct Alzheimer's amyloid beta-peptide generation. EMBO J. 2004;23(3):483-8.

5. Busciglio J, Lorenzo A, Yeh J, Yankner BA. Beta-amyloid fibrils induce tau phosphorylation and loss of microtubule binding. Neuron. 1995;14(4):879-88.

6. McGeer EG, McGeer PL. Inflammatory processes in Alzheimer's disease. Prog Neuropsychopharmacol Biol Psychiatry. 2003;27(5):741-9.
7. Akiyama $\mathrm{H}$, et al. Cell mediators of inflammation in the Alzheimer disease brain. Alzheimer Dis Assoc Disord. 2000;14(Suppl 1):S47-53.

8. Alvarez-Arellano L, et al. Autophagy impairment by caspase-1-dependent inflammation mediates memory loss in response to beta-amyloid peptide accumulation. J Neurosci Res. 2018;96(2):234-46.

9. Heneka MT, et al. NLRP3 is activated in Alzheimer's disease and contributes to pathology in APP/PS1 mice. Nature. 2013;493(7434):674-8.

10. Farooqui AA, Farooqui T, Panza F, Frisardi V. Metabolic syndrome as a risk factor for neurological disorders. Cell Mol Life Sci. 2012;69(5):741-62.

11. Mayeux R, Stern Y. Epidemiology of Alzheimer disease. Cold Spring Harb Perspect Med. 2012;2(8).

12. Biessels GJ, Staekenborg S, Brunner E, Brayne C, Scheltens P. Risk of dementia in diabetes mellitus: a systematic review. Lancet Neurol. 2006;5(1):64-74.

13. Farris $W$, et al. Insulin-degrading enzyme regulates the levels of insulin, amyloid beta-protein, and the beta-amyloid precursor protein intracellular domain in vivo. Proc Natl Acad Sci U S A. 2003;100(7):4162-7.

14. De Felice FG, Ferreira ST. Inflammation, defective insulin signaling, and mitochondrial dysfunction as common molecular denominators connecting type 2 diabetes to Alzheimer disease. Diabetes. 2014;63(7):2262-72.

15. Song J, Lee JE. Adiponectin as a new paradigm for approaching Alzheimer's disease. Anat Cell Biol. 2013;46(4):229-34.

16. Yamanaka M, et al. PPARgamma/RXRalpha-induced and CD36-mediated microglial amyloid-beta phagocytosis results in cognitive improvement in amyloid precursor protein/presenilin 1 mice. J Neurosci. 2012;32(48):17321-31.

17. Lim GP, et al. Ibuprofen effects on Alzheimer pathology and open field activity in APPsw transgenic mice. Neurobiol Aging. 2001;22(6):983-91.

18. Pedraza-Alva G, et al. From traditional remedies to cutting-edge medicine: using ancient Mesoamerican knowledge to address complex disorders relevant to psychoneuroimmunology. Brain Behav Imm. 2019. https://doi. org/10.1016/j.bbi.2019.04.022.

19. Pedraza-Alva G, et al. Negative regulation of the inflammasome: keeping inflammation under control. Immunol Rev. 2015;265:231-57.

20. Perez Gutierrez RM. Evaluation of hypoglycemic activity of the leaves of Malva parviflora in streptozotocin-induced diabetic rats. Food Func. 2012; 3(4):420-7.

21. Bouriche $H$, Meziti $H$, Senator A, Arnhold J. Anti-inflammatory, free radicalscavenging, and metal-chelating activities of Malva parviflora. Pharm Biol. 2011;49(9):942-6.

22. Tai MM. A mathematical model for the determination of total area under glucose tolerance and other metabolic curves. Diabet Care. 1994;17(2):152-4.

23. Bolte $\mathrm{S}$, Cordelieres FP. A guided tour into subcellular colocalization analysis in light microscopy. J Microsc. 2006;224(Pt 3:213-32.

24. Tejerizo GT, et al. Development of molecular tools to monitor conjugative transfer in rhizobia. J Microbiol Methods. 2015;117:155-63.

25. Luo Y, Isaac BM, Casadevall A, Cox D. Phagocytosis inhibits F-actin-enriched membrane protrusions stimulated by fractalkine (CX3CL1) and colonystimulating factor 1. Infect Immun. 2009;77(10):4487-95.

26. Lucin KM, et al. Microglial beclin 1 regulates retromer trafficking and phagocytosis and is impaired in Alzheimer's disease. Neuron. 2013;79(5):873-86.

27. Perez-Martinez $L$, et al. Dexamethasone rapidly regulates TRH mRNA levels in hypothalamic cell cultures: interaction with the CAMP pathway. Neuroendocrinology. 1998;68(5):345-54.

28. Livak KJ, Schmittgen TD. Analysis of relative gene expression data using real-time quantitative PCR and the 2(-Delta Delta C(T)) Method. Methods. 2001;25(4):402-8.

29. Dineley KT, Jahrling JB, Denner L. Insulin resistance in Alzheimer's disease. Neurobiol Dis. 2014;72 Pt A:92-103.

30. Heneka MT, et al. Neuroinflammation in Alzheimer's disease. Lancet Neurol. 2015;14(4):388-405.

31. Julien C, et al. High-fat diet aggravates amyloid-beta and tau pathologies in the 3xTg-AD mouse model. Neurobiol Aging. 2010;31(9):1516-31.

32. Mhatre SD, Tsai CA, Rubin AJ, James ML, Andreasson Kl. Microglial malfunction: the third rail in the development of Alzheimer's disease. Trends Neurosci. 2015;38(10):621-36.

33. Hickman SE, Allison EK, El Khoury J. Microglial dysfunction and defective beta-amyloid clearance pathways in aging Alzheimer's disease mice. J Neurosci. 2008;28(33):8354-60.

34. Malm TM, Jay TR, Landreth GE. The evolving biology of microglia in Alzheimer's disease. Neurotherapeutics. 2015;12(1):81-93.

35. Bolmont T, et al. Dynamics of the microglial/amyloid interaction indicate a role in plaque maintenance. J Neuroscience. 2008;28(16):4283-92. 
36. Stewart CR, et al. CD36 ligands promote sterile inflammation through assembly of a Toll-like receptor 4 and 6 heterodimer. Nat Immunol. 2010; 11(2):155-61.

37. Tam WY, Ma CH. Bipolar/rod-shaped microglia are proliferating microglia with distinct M1/M2 phenotypes. Sci Rep. 2014;4:7279.

38. Walker DG, Lue LF. Immune phenotypes of microglia in human neurodegenerative disease: challenges to detecting microglial polarization in human brains. Alzheimers Res Ther. 2015;7(1):56.

39. McCarthy RC, et al. Characterization of a novel adult murine immortalized microglial cell line and its activation by amyloid-beta. J Neuroinflammation. 2016;13:21.

40. Takahashi K, Rochford CD, Neumann H. Clearance of apoptotic neurons without inflammation by microglial triggering receptor expressed on myeloid cells-2. J Exp Med. 2005;201(4):647-57.

41. Chang WC, et al. Scopoletin protects against methylglyoxal-induced hyperglycemia and insulin resistance mediated by suppression of advanced glycation endproducts (AGEs) generation and anti-glycation. Molecules. 2015;20(2):2786-801

42. Camer D, Yu Y, Szabo A, Huang XF. The molecular mechanisms underpinning the therapeutic properties of oleanolic acid, its isomer and derivatives for type 2 diabetes and associated complications. Mol Nutr Food Res. 2014;58(8):1750-9.

43. Kang $X$, et al. Oleanolic acid prevents cartilage degeneration in diabetic mice via PPARgamma associated mitochondrial stabilization. Biochem Biophys Res Commun. 2017:490(3):834-40.

44. Croasdell A, et al. PPARgamma and the innate immune system mediate the resolution of inflammation. PPAR Res. 2015:2015:549691.

45. Pelzer T, et al. Pioglitazone reverses down-regulation of cardiac PPARY expression in Zucker diabetic fatty rats. Biochem Biophis Res Commun. 2005;329:726-32

46. Leesnitzer LM, et al. Functional consequences of cysteine modification in the ligand binding sites of peroxisome proliferator activated receptors by GW9662. Biochemistry. 2002;41(21):6640-50.

47. Tontonoz P, Nagy L, Alvarez JG, Thomazy VA, Evans RM. PPARgamma promotes monocyte/macrophage differentiation and uptake of oxidized LDL. Cell. 1998;93(2):241-52.

48. Obulesu M, Rao DM. Effect of plant extracts on Alzheimer's disease: an insight into therapeutic avenues. J Neurosci Rural Pract. 2011;2(1):56-61.

49. Kure C, Timmer J, Stough C. The immunomodulatory effects of plant extracts and plant secondary metabolites on chronic neuroinflammation and cognitive aging: a mechanistic and empirical review. Front Pharmacol. 2017;8:117.

50. Farhan H, Rammal H, Hijazi A, Hamad H, Daher A, Reda M, Badran B. In vitro antioxidant activity of ethanolic and aqueous extracts from crude Malva parviflora L. grown in Lebanon. Asian J Pharmaceutic Clin Res. 2012;5:234-8.

51. Aslam M, Sial AA. Neuroprotective effect of ethanol extract of leaves of Malva parviflora against amyloid-beta- (Abeta-) mediated Alzheimer's disease. Int Sch Res Notices. 2014;2014:156976.

52. Zeng $Y$, et al. Tripchlorolide improves cognitive deficits by reducing amyloid beta and upregulating synapse-related proteins in a transgenic model of Alzheimer's Disease. J Neurochem. 2015;133(1):38-52

53. Park H, et al. Anti-amyloidogenic effects of ID1201, the ethanolic extract of the fruits of Melia toosendan, through activation of the phosphatidylinositol 3-kinase/Akt pathway. Environ Toxicol Pharmacol. 2014;37(2):513-20

54. Cho WH, et al. ID1201, the ethanolic extract of the fruit of Melia toosendan ameliorates impairments in spatial learning and reduces levels of amyloid beta in 5XFAD mice. Neurosci Lett. 2014;583:170-5.

55. Oakley $\mathrm{H}$, et al. Intraneuronal beta-amyloid aggregates, neurodegeneration, and neuron loss in transgenic mice with five familial Alzheimer's disease mutations: potential factors in amyloid plaque formation. J Neurosci. 2006; 26(40):10129-40

56. Ho L, et al. Diet-induced insulin resistance promotes amyloidosis in a transgenic mouse model of Alzheimer's disease. FASEB J. 2004;18(7):902-4.

57. Pereira Dos Santos Nascimento MV, et al. Inhibition of the NF-kappaB and p38 MAPK pathways by scopoletin reduce the inflammation caused by carrageenan in the mouse model of pleurisy. Immunopharmacol Immunotoxicol. 2016;38(5):344-52.

58. Tran TA, McCoy MK, Sporn MB, Tansey MG. The synthetic triterpenoid CDDOmethyl ester modulates microglial activities, inhibits TNF production, and provides dopaminergic neuroprotection. J Neuroinflammation. 2008:5:14
59. Knight EM, Martins IV, Gumusgoz S, Allan SM, Lawrence CB. High-fat dietinduced memory impairment in triple-transgenic Alzheimer's disease (3xTgAD) mice is independent of changes in amyloid and tau pathology. Neurobiol Aging. 2014;35(8):1821-32.

60. Moser VA, Pike CJ. Obesity accelerates alzheimer-related pathology in APOE4 but not APOE3 mice. eNeuro. 2017:4:3

61. Petrov D, et al. High-fat diet-induced deregulation of hippocampal insulin signaling and mitochondrial homeostasis deficiences contribute to Alzheimer disease pathology in rodents. Biochim Biophys Acta. 2015;1852(9):1687-99.

62. Vandal $M$, et al. Insulin reverses the high-fat diet-induced increase in brain Abeta and improves memory in an animal model of Alzheimer disease. Diabetes. 2014;63(12):4291-301.

63. Liu Z, et al. High-fat diet induces hepatic insulin resistance and impairment of synaptic plasticity. PloS One. 2015;10(5):e0128274.

64. Spinelli $M$, et al. Brain insulin resistance impairs hippocampal synaptic plasticity and memory by increasing GluA1 palmitoylation through FoxO3a. Nat Commun. 2017:8(1):2009.

65. Stranahan AM, et al. Diet-induced insulin resistance impairs hippocampal synaptic plasticity and cognition in middle-aged rats. Hippocampus. 2008; 18(11):1085-8

66. Lin B, et al. High-fat-diet intake enhances cerebral amyloid angiopathy and cognitive impairment in a mouse model of Alzheimer's disease, independently of metabolic disorders. J Am Heart Assoc. 2016;5(6).

67. Stern SA, Chen DY, Alberini CM. The effect of insulin and insulin-like growth factors on hippocampus- and amygdala-dependent long-term memory formation. Learn Mem. 2014;21(10):556-63.

68. Moosavi M, Naghdi N, Choopani S. Intra CA1 insulin microinjection improves memory consolidation and retrieval. Peptides. 2007;28(5):1029-34.

69. Tucsek $Z$, et al. Obesity in aging exacerbates blood-brain barrier disruption, neuroinflammation, and oxidative stress in the mouse hippocampus: effects on expression of genes involved in beta-amyloid generation and Alzheimer's disease. J Gerontol A Biol Sci Med Sci. 2014;69(10):1212-26.

70. Bomfim TR, et al. An anti-diabetes agent protects the mouse brain from defective insulin signaling caused by Alzheimer's disease- associated Abeta oligomers. J Clin Invest. 2012;122(4):1339-53.

71. Biessels GJ, Reagan LP. Hippocampal insulin resistance and cognitive dysfunction. Nat Rev Neurosci. 2015;16(11):660-71.

72. Cho SO, et al. (2009) Aralia cordata protects against amyloid beta protein (25-35)-induced neurotoxicity in cultured neurons and has antidementia activities in mice. J Pharmacol Sci 111( ):22-32.

73. Hornick A, et al. The coumarin scopoletin potentiates acetylcholine release from synaptosomes, amplifies hippocampal long-term potentiation and ameliorates anticholinergic- and age-impaired memory. Neuroscience. 2011;197:280-92.

74. Buckingham SD, Jones AK, Brown LA, Sattelle DB. Nicotinic acetylcholine receptor signalling: roles in Alzheimer's disease and amyloid neuroprotection. Pharmacol Rev. 2009:61(1):39-61.

75. Heneka MT, O'Banion MK. Inflammatory processes in Alzheimer's disease. Neuroimmunol. 2007;184(1-2):69-91.

76. Njie EG, et al. Ex vivo cultures of microglia from young and aged rodent brain reveal age-related changes in microglial function. Neurobiol Aging. 2012;33(1):195 e191-12.

77. Kleinberger $\mathrm{G}$, et al. TREM2 mutations implicated in neurodegeneration impair cell surface transport and phagocytosis. Sci Transl Med. 2014;6(243):243ra286.

78. Wang $Y$, et al. TREM2-mediated early microglial response limits diffusion and toxicity of amyloid plaques. J Exp Med. 2016;213(5):667-75.

79. Brendel M, et al. Increase of TREM2 during Aging of an Alzheimer's disease mouse model is paralleled by microglial activation and amyloidosis. Front Aging Neurosci. 2017;9:8

80. Keren-Shaul $H_{\text {, et }}$ al. A unique microglia type associated with restricting development of Alzheimer's disease. Cell. 2017;169(7):1276-1290 e1217.

81. Wang $Y$, et al. TREM2 lipid sensing sustains the microglial response in an Alzheimer's disease model. Cell. 2015;160(6):1061-71.

82. Sims-Robinson C, Kim B, Rosko A, Feldman EL. How does diabetes accelerate Alzheimer disease pathology? Nat Rev Neurol. 2010;6(10):551-9.

\section{Publisher's Note}

Springer Nature remains neutral with regard to jurisdictional claims in published maps and institutional affiliations. 